\title{
Misuse Detection for a Generalized SFR Test Reactor
}

\section{January 2021}

Samuel E Bays, Ryan Hunter Stewart, Frederick N Gleicher, Nicolas Pierre Martin

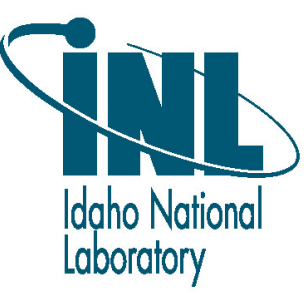




\section{DISCLAIMER}

This information was prepared as an account of work sponsored by an agency of the U.S. Government. Neither the U.S. Government nor any agency thereof, nor any of their employees, makes any warranty, expressed or implied, or assumes any legal liability or responsibility for the accuracy, completeness, or usefulness, of any information, apparatus, product, or process disclosed, or represents that its use would not infringe privately owned rights. References herein to any specific commercial product, process, or service by trade name, trade mark, manufacturer, or otherwise, does not necessarily constitute or imply its endorsement, recommendation, or favoring by the U.S. Government or any agency thereof. The views and opinions of authors expressed herein do not necessarily state or reflect those of the U.S. Government or any agency thereof. 


\section{Misuse Detection for a Generalized SFR Test Reactor}

Samuel E Bays, Ryan Hunter Stewart, Frederick N Gleicher, Nicolas Pierre Martin

January 2021

Idaho National Laboratory

Idaho Falls, Idaho 83415

http://www.inl.gov

Prepared for the

U.S. Department of Energy

Under DOE Idaho Operations Office

Contract DE-AC07-05ID14517 


\section{IAEA Diversion and Misuse Detection for a Generalized SFR Test Reactor}

January 2021

F. N. Gleicher

R. H. Stewart

N. P. Martin

S. E. Bays

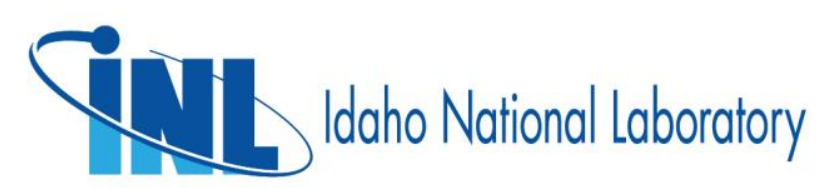




\section{DISCLAIMER}

This information was prepared as an account of work sponsored by an agency of the U.S. Government. Neither the U.S. Government nor any agency thereof, nor any of their employees, makes any warranty, expressed or implied, or assumes any legal liability or responsibility for the accuracy, completeness, or usefulness, of any information, apparatus, product, or process disclosed, or represents that its use would not infringe privately owned rights. References herein to any specific commercial product, process, or service by trade name, trademark, manufacturer, or otherwise, does not necessarily constitute or imply its endorsement, recommendation, or favoring by the U.S. Government or any agency thereof. The views and opinions of authors expressed herein do not necessarily state or reflect those of the U.S. Government or any agency thereof. 
INL/EXT-21-61292

Revision 0

\title{
IAEA Diversion and Misuse Detection for a Generalized SFR Test Reactor
}

\author{
F. N. Gleicher, R. H. Stewart, N. P. Martin, S. E. Bays
}

January 2021

Idaho National Laboratory

Idaho Falls, Idaho 83415 

Work Supported through NA-22

\title{
IAEA Diversion and Misuse Detection for a Generalized SFR Test Reactor
}

\author{
INL/EXT-21-61292 \\ Revision 0
}

January 2021

Approved by:

Name

Title [optional]

Name

Title [optional]

Name

Title [optional]

Name

Title [optional]

Date

Date

Date 



\section{SUMMARY}

Sodium-cooled Fast Reactors (SFRs) present unique challenges for international safeguards. SFRs possess neutron physics characteristics that if configured appropriately could produce more fissile material than consumed. An adversary state may choose to build or buy an SFR, justified by a lack of domestic natural uranium and limited access or interest to procure uranium from international markets. Once the SFR is constructed, the state may choose to operate the SFR, that has been declared to the International Atomic Energy Agency (IAEA), for the purpose of diverting declared nuclear material or to misuse it to produce fissile plutonium. This work shows that a demonstration ${ }^{\mathrm{a}}$ SFR does not need to be configured as a plutonium breeder ${ }^{\mathrm{b}}$ to create one Significant Quantity (SQ) ${ }^{\mathrm{c}}$ of plutonium in a short amount of time (e.g., 1 to a few years). However, expediting the diversion or misuse to create $1 \mathrm{SQ}$ in one to two operating cycles would change the core reactivity in a way that would be easily indicated by deviations of control rod position when compared to the state's declared operation.

In this work, a contrived SFR demonstration reactor was modeled for the purpose of exploring proliferation scenarios and how such diversion and misuse could be detected using the SFR's Reactor Data Acquisition System (RDAS). Typically, the International Atomic Energy Agency (IAEA) does not have continuous and authenticated access to the control rod position, power, thermal, or pressure-sensing and indicating systems of nuclear power plants. The access to this data on a continuous and authenticated basis will not be addressed here. Only the advantages of that data access will be assessed. However, this work shows that such data streams can be compared against a parallel detailed simulation model (a digital twin) to detect possible proliferation.

In the more subtle misuse cases analyzed (i.e., less fertile material per cycle), the $1 \mathrm{SQ}$ can be created in roughly 10 years. These scenarios involved replacing one to 12 fuel-rods from every driver fuel-assembly (each having 217 rods in

a A "demonstration" reactor is a form of test research reactor intended to demonstrate fuel performance and overall reactor safety to enable licensing of commercial nuclear power plants of similar design.

${ }^{\mathrm{b}}$ A plutonium breeder can create more fissile plutonium via 1n capture in U238 than is destroyed (mostly by fission). Typically, research/test/demonstration SFRs have a Conversion Ratio (CR) (i.e., the ratio of plutonium production rate per destruction rate), of less than unity $(\mathrm{CR}<1)$.

${ }^{\mathrm{c}}$ This is a different paradigm for analyzing SFRs. Usually, an SFR is defined as a plutonium burner $(\mathrm{CR}<1)$ or breeder $(\mathrm{CR}>1)$. This work shows that while it is technically feasible to misuse the SFR to create one SQ undeclared while the declared operation remains holistically a net plutonium burner, such diversion or misuse is detectable by monitoring the RDAS data stream. 
total) with fertile U-238 rods. Other scenarios involved analyzing one full fuelassembly (fertile target) of U-238 rods located in the designated experiment locations of the demonstration SFR.

A less patient proliferator would place fertile targets in the highest flux test locations toward the center of the SFR. These extreme misuse cases can be detected by comparing the control rod position at initial startup with the declared startup position. To create the $1 \mathrm{SQ}$ in one to two years, the required amount of fertile uranium changes core reactivity sufficiently to necessitate a change in the required control rod position to start the reactor.

Also, such significant additions of fertile material (approximately four or more target assemblies) slightly increases the core conversion ratio (CR), though not more than unity. When fertile targets are fresh, the fertile U-238 absorbs surplus neutrons. This causes the control rods being withdrawn further out than declared when the reactor first achieves criticality. As plutonium appreciably builds up in the targets, it adds neutrons to the chain reaction. These added neutrons, called excess reactivity, causes the control rods to be inserted further in than declared at the end of the cycle.

It was found that such CR biases can potentially be masked by addition of various high neutron scattering $(\mathrm{Pb})$ or absorbing $(\mathrm{Ni})$ assemblies in the demonstration SFR's designated test assembly locations. Disclosure of irradiating materials that are not Special Nuclear Materials (SNM), e.g., $\mathrm{Pb}$ and $\mathrm{Ni}$, is not a requirement of declared operation. Such scenarios could lead to $1 \mathrm{SQ}$ acquisition in one to a few cycles if sufficient undeclared targets can be inserted without being detected by traditional safeguards practices, (i.e., item counting and attribute measurements).

A possible remedy of this sensing gap is to provide the reactor design with an "instrument tree". An instrument tree locates thermocouples and flow meters above the fuel assemblies along three of the six hexagonal axes of the active core. Such an instrument tree would likely detect placement of two or more fertile targets grouped together in the core radial periphery.

The scenarios analyzed provide insight into the mindset of would-be proliferating state/SFR operators and demonstrate how such diversion or misuse actions can be detected using existing reactor plant monitoring equipment. Such safeguards by remote sensing follows the safeguards-by-design philosophy and uses equipment that is common to most nuclear power plants (and SFRs). This work focusses solely on nuclear weapons proliferation using SFRs, but it also establishes the reactor physics models and general knowledge for combining the computational model into a more robust and data-rich digital twin data ontology. 


\section{CONTENTS}

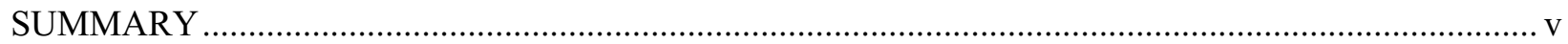

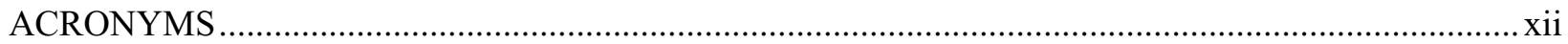

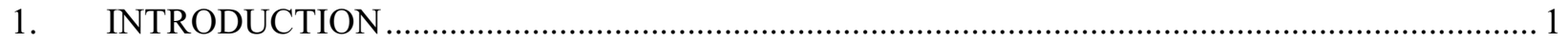

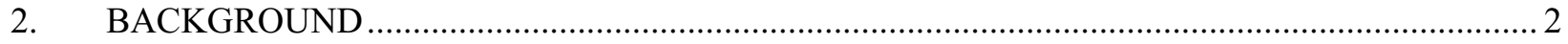

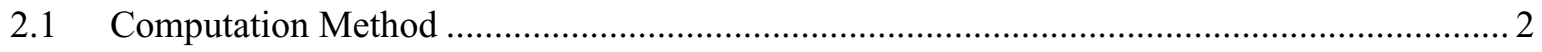

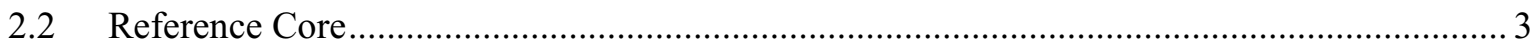

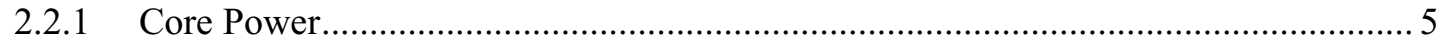

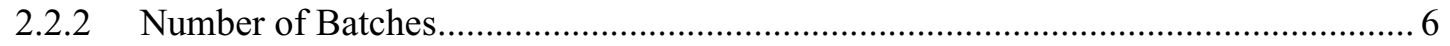

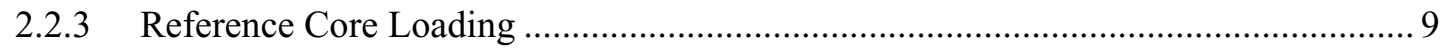

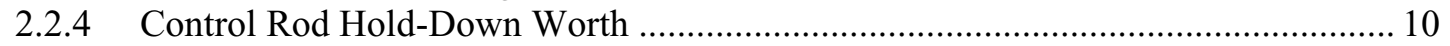

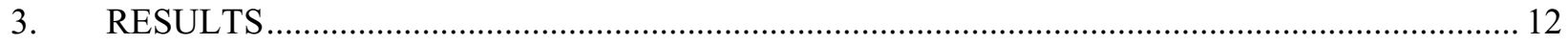

3.1 Scenario 1: Diverted Fuel Rods(s) in All Driver Fuel Assemblies ..................................... 12

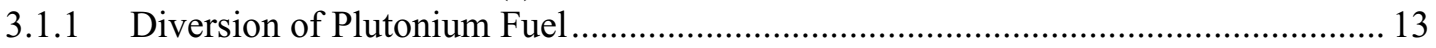

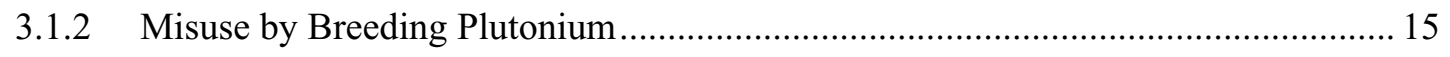

3.2 Scenario 2: One U-238 Assembly in an Experiment Location ........................................... 17

3.2.1 Location of a Single U-238 Assembly ................................................................ 17

3.2.2 Linear Combination of Single U-238 Assembly Production Rates ........................... 19

3.3 Scenario 3. Multiple U-238 Assemblies in Experiment Locations ..................................... 21

3.3.1 Start-up Control Rod Position for Multiple U-238 Assemblies ................................ 22

3.3.2 Masking U-238 Assemblies with Typical Materials Testing ......................................2 23

3.3.3 Detecting U-238 Assemblies via Power Distortions............................................. 24

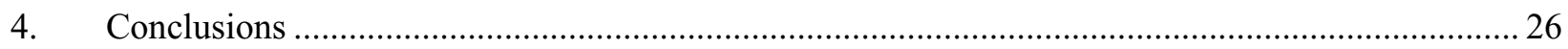

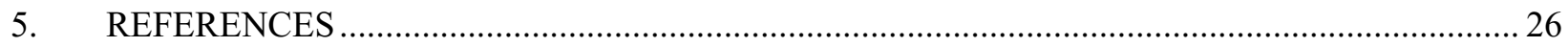

\section{FIGURES}

Figure 1. Digital twin reference showing experiment locations. Grey locations indicate control rods. Green locations indicate experiment assembly locations. The numbered arrows indicate the row number.

Figure 2. Full-power-days required to reach a peak burnup of 10\% FIMA for a core power of 250 MWth and 300 MWth.

Figure 3. Change in k-eff with time for core power of $250 \mathrm{MWth}$ and $300 \mathrm{MWth}$ 8

Figure 4. Core reactivity comparison between single-batch, two-batch, and three-batches using the linear reactivity model as well as the actual core reactivity for the 3-D physical model.

Figure 5. Three-batch core configuration without shuffling, where fresh fuel is seen in blue, once burned fuel in orange, twice burned fuel in red, and experimental/safety/control positions in black. 
Figure 6. k-eff curve as a function of control rod insertion depth for natural and 85 a/o B-10 control rods.

Figure 7. Integral control rod worth for natural and $85 \mathrm{a} / \mathrm{o}$ B-10 control rods.

Figure 8. Diagrams of diversion rod positions in a single assembly. (A.) Single diversion rod, (B.) Two diversion rods (C.) Four diversion rods (D.) Eight diversion rods (E.) Twelve diversion rods.

Figure 9. Calculated average midplane maximum linear power for a central hexagonal assembly versus time for all fresh core.

Figure 10. k-eff for a three-batch core to 400 Full-Power-Days assuming one, two, four, eight, or 12- fuel rods per every assembly are replaced by ${ }^{\text {nat }} \mathrm{U}-10 \mathrm{Zr}$ surrogate-rods. 16

Figure 11. Plutonium produced by a thrice burned batch for $1,2,4,8,12{ }^{\text {nat }} \mathrm{U}-10 \mathrm{Zr}$ surrogaterods. Note that this plot shows the plutonium created in ${ }^{\text {nat }} \mathrm{U}-10 \mathrm{Zr}$ rods for one batch of fuel over three cycles of irradiation.

Figure 12. Plutonium mass generated for a single FEA located in one experiment location in row $1,3,5$, or 6 . 18

Figure 13. k-eff for a single FEA located in one experiment location in row 1, 3, 5, or 6.

Figure 14. Plutonium mass generation for utilization of all experiment positions in rows 3, 5, or 6.

Figure 15. Reactivity perturbation from the reference case: one FEA in the test location in row 1, three in the test locations of row 3 , three in the test locations of row 5, or six in the six vertex reflector locations of row 6.

Figure 16. Critical control rod height for varied number of experiments place in the core.

Figure 17. Misuse scenario with three fertile targets (one in row 1, two in row 5).

Figure 18. Reactivity influence of inserting three target assemblies (one inner, two outer) having fertile versus inert material types. The unit of penti-centi-milli $(\mathrm{pcm})$ is $1 \mathrm{E} 5 \times \Delta \mathrm{k}$.

Figure 19. Core configuration for examining assembly power, yellow assemblies indicate FEAs, black assemblies indicate control/safety rods or unused experimental positions. 25

Figure 20. Difference in assembly power level for rows 2 and 3 26

\section{TABLES}

Table 1. Plutonium isotopics composition of fresh fuel [6]. 4

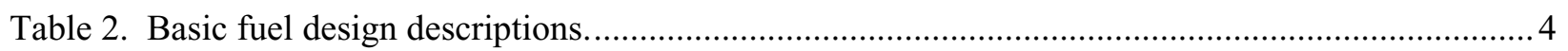

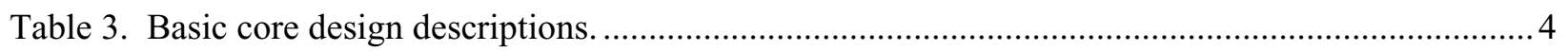

Table 4. Calculated linear power for the center section of the given assembly....................................... 6

Table 5. Cycle-length and residency time in full-power-days for the $250 \mathrm{MWth}$ and $300 \mathrm{MWth}$ power levels assuming different batch schemes.

Table 6. The number of diversion-rods and the modeled critical core eigenvalue (StartUp of 3batch core).

Table 7. Primary control rod position at BOC startup-criticality for one, two, four, eight, or 12 diversion-rods per fuel-assembly. 
Table 8. Plutonium mass generated after one, two, or three cycles. ..................................................... 18

Table 9. Primary control rod position at BOC startup-criticality for 1 FEA placements.......................... 19

Table 10. Plutonium mass estimates for a FEA placed in all experiment locations in row 3..................20

Table 11. Plutonium mass estimates for an FEA placed in the experiment locations of row 1 and

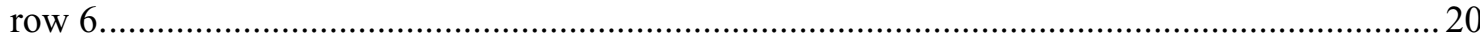




\section{ACRONYMS}

\begin{tabular}{ll} 
ABR & Advanced Burner Reactor \\
ABTR & Advanced Burner Test Reactor \\
BOC & Beginning of cycle \\
CR & Conversion ratio \\
DOE & Department of Energy \\
EFPD & Effective Full Power Days \\
EOC & End-of-cycle \\
FFTF & Fast Flux Test Facility \\
FEA & Fertile Experiment Assembly \\
FIMA & Fissions per Initial Metal Atom \\
GNEP & Global Nuclear Energy Partnership \\
IAEA & International Atomic Energy Agency \\
LHGR & Linear Heat Generation Rate \\
LMFBR & Liquid Metal Fast Breeder \\
NPT & Non-Proliferation Treaty \\
RDAS & Reactor Data Acquisition System \\
SFR & Sodium-cooled Fast Reactor \\
SQ & Significant quantity \\
VTR & Versatile Test Reactor \\
WG & Weapons Grade \\
\hline
\end{tabular}




\section{Diversion and Misuse Detection for a Generalized SFR Test Reactor}

\section{INTRODUCTION}

Sodium-cooled Fast Reactors (SFRs) present unique challenges for international safeguards. SFRs have largely not been used for plutonium production for nuclear weapons. Historically, graphite-pile or heavy water reactors have been used to produce the defense plutonium stockpiles by the world's weapon states. However, SFRs possess neutron physics characteristics that, if configured appropriately, could produce more fissile material than consumed. The genesis of SFRs, or Liquid Metal Fast Breeder (LMFBR), was to enable nuclear expansion in a time when uranium was considered scarce. In practice, most SFRs historically operated as materials irradiation testbeds. Thus, the ratio of fissile produced to fissile destroyed, called the conversion ratio (CR), is $\mathrm{CR}<1$ for most research and demonstration SFRs.

An adversary state may choose to build or buy a demonstration SFR with the stated goal of eventually producing a fleet of LMFBRs. A demonstration SFR is considered a type of research reactor designed to demonstrate fuel performance and safety characteristics used to gain confidence leading to commercial licensing. Acquiring commercial LMFBR technology may be justified by a lack of domestic natural uranium and limited access or interest to procure uranium from international markets. Once constructed, the state may choose to proliferate by using the demonstration SFR for the purpose of diverting fissile uranium/plutonium from the plutonium-bearing fuel manufacturing plant, or misuse the SFR to produce plutonium target uranium while declaring normal operation. Detecting SFR misuse is complicated by the fact that normal inspections involve item-counting by confirming serial numbers under water using cameras. Sodium is opaque, thus requiring specialized technology (e.g., ultrasound, radiation signature identification) to perform traditional ex-core material safeguards or more routine LWR-like activities after cleaning and canning of fuel assemblies.

Typically, the International Atomic Energy Agency (IAEA) does not have access to the control rod position, power level, thermal, pressure sensing and indicating systems of nuclear power plants. However, this work shows that such data streams can be useful for comparing against a parallel detailed simulation model (a digital twin) to detect possible diversion or misuse. This work shows that a demonstration SFR with $\mathrm{CR}<1$ does not need to be configured such that $\mathrm{CR}>1$, (i.e., a LMFBR), in order to create a Significant Quantity (SQ) of plutonium in a short amount of time (e.g., 1 to a few years). For the purpose of this work, $1 \mathrm{SQ}$ is $8 \mathrm{~kg}$ of Weapons Grade (WG) plutonium $\left({ }^{240} \mathrm{Pu} / \mathrm{Pu} \leq 6 \%\right)$ or WGPu. However, reactor diversion or misuse would change the core reactivity in such a way as to be easily indicated by deviations of control rod position compared to declared operation.

To model surveillance of declared operation (e.g., temperature, pressure, power level, cycle-length), existing nuclear models of the Advanced Burner Reactor (ABR) and Advanced Burner Test Reactor (ABTR) were leveraged and modified into the reference physics model for the digital twin. ABR is an SFR concept developed by the US Department of Energy (DOE) national laboratories to demonstrate actinide burning (not breeding) for the Global Nuclear Energy Partnership (GNEP) of the 2000's. The thermal power for the ABR was 1,000 MWth. ABTR was a smaller (250 MWth) demonstration reactor used to gain confidence in high-transuranic-content fast-reactor fuel before building the larger ABR. The current Versatile Test Reactor (VTR) concept currently under consideration by DOE draws heavily from the previous ABTR design studies. It should be noted though that this report documents a hypothetical digital twin of a generalized SFR, not the VTR.

The digital twin simulation model represents a typical operating cycle at a demonstration SFR. No effort was made to 'optimize' the fast flux in the central regions of the core. This is a priority for the VTR project. However, for this early effort, the digital twin is assumed to be a "demonstration" reactor. Thus, simply building experience with operating the SFR is the primary objective of the plant operator. A 
reference cycle consisting of fresh, once-burned, and twice-burned fuel was constructed to represent a typical operating cycle. This reference model represents declared operation by the operator. Then various reactor diversion and misuse scenarios were investigated using the reference computational model as a starting point.

The diversion scenarios involve replacement of one, two, four, eight, or 12- fuel-rods in every assembly with either lead $(\mathrm{Pb})$, stainless steel (SS), or natural uranium fertile-rods ( $\left.{ }^{\text {nat }} \mathrm{U}-10 \mathrm{Zr}\right)$. Here we assume the operator is diverting one, two, four, eight, or 12- fuel-rods for a clandestine weapons program. There are normally $217^{\text {nat }} \mathrm{U}-15 \mathrm{Pu}-10 \mathrm{Zr}$ containing fuel rods per driver fuel-assembly. The plutonium feedstock for fuel-rods could be from declared reprocessing of a domestic spent nuclear fuel inventory. It is possible, though less likely, that the operator could deconstruct finished fuel assemblies imported from an external fuel supplier in a lease/take-back agreement in order to replace the desired fuel-rods. One could assume that if ${ }^{\text {nat }} \mathrm{U}-10 \mathrm{Zr}$ rods were placed into each driver assembly, these rods could be extracted following their three cycles in the core. This would be considered a reactor misuse scenario because proliferation is occurring with undeclared material. However, this would require complex remote fuel handling operations as the ${ }^{\text {nat }} \mathrm{U}-10 \mathrm{Zr}$ rods would be protected by the radiation field produced by the irradiated ${ }^{\text {nat }} \mathrm{U}-15 \mathrm{Pu}-10 \mathrm{Zr}$ rods.

The second scenario involves placement of a whole assembly (referred to as targets) of fertile ${ }^{\text {nat }} \mathrm{U}$ $10 \mathrm{Zr}$ rods in an experiment test location within the reactor. This scenario is considered reactor misuse because insertion of source material is not declared. In such scenarios, the rate of plutonium production increases for target assemblies placed nearer the high flux central location. However, placing fertile material in higher neutronically important regions increases the likely control rod deviation from declared operation.

The third scenario involves placing multiple targets in the core to acquire 1 SQ in one cycle (400 days). These scenarios are also considered to be reactor misuse. For increasing number of undeclared fertile targets within and surrounding the active core, the CR approaches unity (i.e., the same amount of fissile material is created as is consumed) ${ }^{\mathrm{d}}$. Placing fertile targets in the outer core (or in the radial reflector), decreases the impact on core reactivity, and hence may not be detected by control rod deviations. Therefore, it may be necessary to provision the SFR with an instrument tree; a device containing thermocouples and flow-meters above select fuel assemblies to correlate sodium temperature and flows exiting the fuel-assembly with fuel-assembly power level.

\section{BACKGROUND}

\subsection{Computation Method}

The Serpent (version 2.1.2) Monte Carlo code has a widespread user community and has emerged as one of the leading Monte Carlo codes for reactor physics applications over the last few years [1]. At this moment, the code is freely available for research purposes, and is not distributed with a comprehensive validation report. However, many examples of validation cases pertaining to fast reactors can be found in the open literature. Here is a sample of recent validation work done by various institutions specifically for fast spectrum reactors, using either Serpent as a standalone reactor physics code and/or as a cross section generator for use in a nodal transport code. The results reported in these studies demonstrate that the Serpent code is mature enough for this type of work.

1. Modeling of the FFTF ${ }^{\mathrm{e}}$ isothermal physics tests with the Serpent and DYN3D codes, Annals of Nuclear Energy, 132, October 2019, Pages 679-685.

\footnotetext{
${ }^{\mathrm{d}}$ For context, SFRs designed and declared to be $\mathrm{CR}=1$, the fertile targets would be considered breeding blankets.

e FFTF - Fast Flux Test Facility built in Richland, Washington and decommissioned
} 
2. The path for innovative severe accident neutronics studies in $\mathrm{ZPRs}^{\mathrm{f}}-$ Analysis of SNEAK-12B experiments for core disruption in LMFBRs, Annals of Nuclear Energy, 124, February 2019, Pages 119-131.

3. Nuclear data sensitivity and uncertainty analysis of critical VENUS-F cores with the Serpent Monte Carlo code, Annals of Nuclear Energy, 138, April 2020, in press.

4. Validation of the DYN3D-Serpent code system for SFR cores using selected BFS experiments. Part II: DYN3D calculations, Annals of Nuclear Energy, 114, April 2018, Pages 181-190.

5. Extension of the reactor dynamics code DYN3D to SFR applications - Part II: Validation against the Phenix EOL control rod withdrawal tests, 119, September 2018, Pages 411-418.

6. Validation of the Serpent and TRACE codes using the SHRT-17 and SHRT-45R loss-of-flow tests performed in the EBR-II reactors, in proceedings of ICAPP 2015.

\subsection{Reference Core}

Assume that the state constructs a non-breeding, conversion ratio $(\mathrm{CR}<1)$ demonstration SFR with the intent of eventually adding fertile (natural uranium) blankets to approach $\mathrm{CR} \geq 1$. Also, it is assumed that the state will declare fuel and blanket assembly fuel movements prior to operation no matter the conversion ratio. Typically, SFRs are designed with a general CR in mind, but operators can modify the $\mathrm{CR}$ by adding breeding blankets or altering the fertile content in the fuel. However, large deviations in CR changes basic core performances, (e.g., start-up control rod position, cycle-length, coolant flow rates, temperatures, and pressure losses). This information is available from most nuclear power plant's Reactor Data Acquisition System (RDAS). It is hypothesized that attempts by the state to divert or misuse the SFR core to create 1 SQ of plutonium in one year (or one operating cycle of 400 days) will alter reactor operation in a way that is detectable by the IAEA analyst monitoring the RDAS output.

The digital twin reference core is founded on previous work during the GNEP program on the Advanced Burner Reactor (ABR) and Advanced Burner Test Reactor (ABTR) [2] [3]. The ABR was intended to be a 1,000 MWth Sodium-cooled Fast Reactor (SFR) designed to burn transuranic waste generated by commercial nuclear power plants. The ABTR was a $250 \mathrm{MWth}$ materials test reactor designed for irradiation testing and advanced fuels demonstration to support fuel qualification for the ABR.

Many trade-studies were conducted on basic design elements (e.g., conversion ratio [CR], number of control rods needed, general safety coefficients) running up to the ABR conceptual design. Of these a $\mathrm{CR}=1$ concept was produced [2]. In addition to the nuclear design, a detailed thermal-hydraulic analysis of sodium flow within a standard fuel-assembly was performed by Memmott et. al. at MIT on the CR=1 concept [4]. The digital twin reference combines the $\mathrm{CR}=1$ fuel-assembly design studied by Memmott et. al., with a core configuration similar to the ABTR. The resulting core design is a $300 \mathrm{MW}$ th hybrid, which is at the upper power level for a small modular reactor ${ }^{\mathrm{g}}$. The fuel composition for this fuel concept (U-15Pu-10Zr metallic slugs) is bounded by the fuel composition tested in IFR-1 series in the Fast Flux Test Facility (FFTF) (U-8-10Zr and U-19-10Zr) and documented by Porter et. al. [5]. The temperatures, peak rod linear power rates, and peak rod burnups for the digital twin correspond to the IFR-1 test conditions, considered to be prototypical. The fresh fuel plutonium isotopic composition can be seen in Table 1. This plutonium is based on spent fuel from a heavy-water reactor [6]. Table 2 contains a breakdown of relevant fuel design-type information. Table 3 contains basic reactor design type

\footnotetext{
${ }^{\mathrm{f}}$ ZPRs - Zero Power Reactors

g Note that the accepted power rating to be considered an SMR is 300 MWe. Since this concept is 300 MWth (i.e., less than 300 MWe), it can be generalized SFR described here could also be considered an SMR [13].
} 
information. The core power level and cycle-length were selected to approximate the peak rod linear power and fuel burnup of the IFR-1 test.

Table 1. Plutonium isotopics composition of fresh fuel [6].

\begin{tabular}{|c|c|}
\hline Isotope & Weight Percent \\
\hline Pu-238 & 0.14 \\
\hline Pu-239 & 64.92 \\
\hline Pu-240 & 29.44 \\
\hline Pu-241 & 3.23 \\
\hline Pu-242 & 2.27 \\
\hline
\end{tabular}

Table 2. Basic fuel design descriptions.

\begin{tabular}{|c|c|c|c|}
\hline & ABR (CR=1) & ABTR & Digital Twin \\
\hline Assembly pitch (cm) & 16.142 & 14.598 & 14.5 \\
\hline Duct thickness (cm) & 0.432 & 0.300 & 0.394 \\
\hline Assembly gap (cm) & 0.394 & 0.400 & 0.432 \\
\hline Pins per assembly & 271 & 217 & 217 \\
\hline Pin diameter (cm) & 0.808 & 0.800 & 0.808 \\
\hline Clad thickness (cm) & 0.0559 & 0.052 & 0.0559 \\
\hline Wire wrap diameter (cm) & 0.0805 & 0.103 & 1.1 \\
\hline Fuel rod pitch-to-diam & 1.1 & 1.13 & $75 \%$ \\
\hline Smear density (\%) & $75 \%$ & $75 \%$ & 101.6 \\
\hline Fuel height (cm) & 101.6 & 80.0 & \\
\hline
\end{tabular}

Table 3. Basic core design descriptions.

\begin{tabular}{|c|c|c|c|}
\hline & ABR (CR=1) & ABTR & Digital Twin \\
\hline Core power (MW) & 1,000 & 250 & 300 \\
\hline Fuel assemblies & 151 & 54 & 69 \\
\hline Primary CR assemblies & 9 & 7 & 6 \\
\hline Secondary CR assemblies & 3 & 3 & 3 \\
\hline Test locations & 0 & 9 & 7 \\
\hline Peak LHGR (kW/m) & 38.9 & 38.5 & 35 \\
\hline Peak burnup (MWD/kg) & 100.8 & 130.8 & 105 \\
\hline Peak burnup (FIMA \%) & $\sim 9.6$ & $\sim 12 \%$ & 1,200 \\
\hline Fuel residency (days) & 1,110 & 1,826 & 400 \\
\hline Cycle-length (days) & 370 & 122 & $95 \%$ \\
\hline Capacity factor (\%) & & & 20 \\
\hline Outage length (days) & & $12-15$ & 3 \\
\hline Number of batches & 3 & & \\
\hline
\end{tabular}

To ensure a $\mathrm{CR}<1$ for the digital twin reference, we have chosen an arrangement of fuel assemblies closer to the smaller (i.e., greater neutron losses via leakage) ABTR to ensure the reference digital twin is a fissile burner, unless sufficient blankets are added. Note that the ABR and ABTR fuel height is 101.6 $\mathrm{cm}$ and $80 \mathrm{~cm}$, respectively. The ABR and ABTR core diameter was approximately $122 \mathrm{~cm}$ and $74 \mathrm{~cm}$, 
respectively. The digital twin reference core height is $101.6 \mathrm{~cm}$ with a core diameter of $79 \mathrm{~cm}$. Thus, the height-to-diameter ratios for the ABR, ABTR, and digital twin are $0.83,1.08$, and 1.28, respectively.

In the ABR and ABTR concepts, no breeding blankets were considered. This digital twin reference is chosen for the present study as it hypothesizes that the state constructs a $\mathrm{CR}<1$ demonstration SFR with the intent of eventually adding fertile (natural uranium) blankets to approach $\mathrm{CR} \geq 1$. The state is assumed to declare fuel and blanket assembly fuel movements prior to operation no matter the conversion ratio. Adding one row of blankets to the digital twin would increase the diameter to $92 \mathrm{~cm}$, with a height-todiameter ratio of 1.1. The digital twin reference core layout is given in Figure 1.

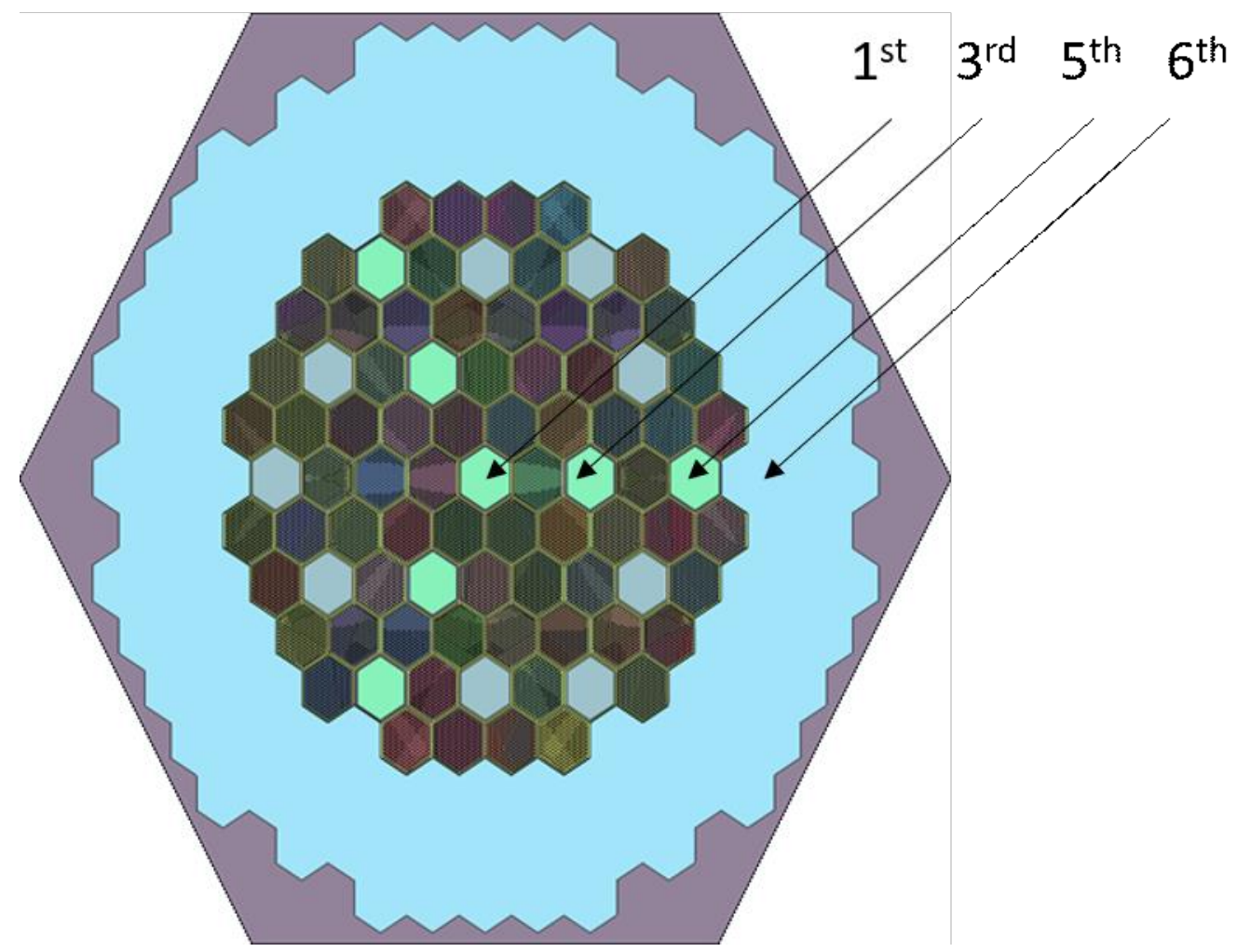

Figure 1. Digital twin reference showing experiment locations. Grey locations indicate control rods. Green locations indicate experiment assembly locations. The numbered arrows indicate the row number.

\subsubsection{Core Power}

In the center of the core, a row of assemblies, which are referred to as the center six assemblies, and in the Serpent model the core is divided into five axial sections $(101.6 / 5=20.32 \mathrm{~cm})$. The middle assembly section is the third axial section. This is considered to be the region in the computation model corresponding to the axial peak power density. Table 4 lists the Serpent results for this middle $(\sim 20 \mathrm{~cm}$ about core midplane) axial section of the six row 2 assemblies. The total powers for these middle central assemblies are computed from the obtained flux and cross-section terms with the thermal power set in Serpent to 300 MWth. The results in the table show that if total power in Serpent is scaled to 300 MWth the computed peak linear power for the rods in the center row assemblies is $\sim 35 \mathrm{~kW} / \mathrm{m}$. The energy obtained from the interactions of both neutrons and gamma rays are estimated by assuming the energy is deposited locally and is scaled according to the neutron reactions through the use of the ' $\mathrm{dr}-8$ ' flag in Serpent. Serpent does have the capability to track both neutron and gamma rays and can provide a more detailed and accurate energy deposition by running a detailed coupled neutron and gamma ray calculation. However, there is a desire to reduce the computational resources needed to run scenario 
studies when coupled with the digital twin's data repository. Tracking gamma-rays in addition to neutrons would require significantly more computational resources and/or wall-clock time.

A core power of 300 MWth gives a peak rod Linear Heat Generation Rate (LHGR) in the centermost fuel assemblies (i.e., the six fuel assemblies in row 2 surrounding the center test location) is $\sim 35 \mathrm{~kW} / \mathrm{m}$. The IFR-1 rods had peak rod linear power as high as $48 \mathrm{~kW} / \mathrm{m}$ when fresh and as low as $29 \mathrm{~kW} / \mathrm{m}$ because of fissile burnup. The value of $35 \mathrm{~kW} / \mathrm{m}$ is representative of many SFRs, including EBR-II (USA), FFTF (USA), MONJU (Japan), and FBTR (India) [7]. Given that the fresh fuel linear power from the IFR-1 test is greater than that assumed for the fresh fuel linear power, there is margin to be utilized by a would-be proliferator. This will be explored in the misuse scenario studies.

Table 4. Calculated linear power for the center section of the given assembly.

\begin{tabular}{|c|c|}
\hline $\begin{array}{c}\text { Assembly } \mathrm{ID}^{+} \\
\text {NW }\end{array}$ & $\begin{array}{c}300 \text { MWth calculated linear power (Neutron only) } \\
{[\mathrm{kW} / \mathrm{m}]}\end{array}$ \\
\hline NE & $3.4853 \mathrm{E}+01$ \\
\hline W & $3.5581 \mathrm{E}+01$ \\
\hline E & $3.5468 \mathrm{E}+01$ \\
\hline SW & $3.4769 \mathrm{E}+01$ \\
\hline SE & $3.4667 \mathrm{E}+01$ \\
\hline
\end{tabular}

Note that each row of the table corresponds to a fuel assembly in row 2 of Figure 1. The cardinal and ordinal directions in this table indicate the azimuthal position in row 2.

\subsubsection{Number of Batches}

To estimate the approximate number of fuel assemblies requiring replacement every year (i.e., a batch), a linear reactivity model was utilized to estimate the excess reactivity of a core containing onebatch, or two-batch, or three-batch. The linear reactivity model is defined as such:

$$
k_{\text {reactor }}=\frac{1}{N} \sum_{n}^{N} k_{n}\left(T_{n}\right)
$$

The equilibrium burnup for an $\mathrm{N}$-batch reactor is given by the equation:

$T_{N}=\frac{2 \times N}{N+1} T_{1}$

The burnup corresponding to cycle-length is given by:

$$
T_{\text {cycle }}=\frac{T_{N}}{N}
$$

Where: $\mathrm{N}$ is the total number of batches comprising the core. $\mathrm{k}_{\text {reactor }}$ is the $\mathrm{k}$-eff of a reactor containing $\mathrm{N}$ batches of fuel, i.e., fresh, once-burned, twice-burned, Nth-burned at reactor startup. $\mathrm{k}_{\mathrm{n}}\left(\mathrm{T}_{\mathrm{n}}\right)$ is the k-eff of the core at $T_{n}$ if it were only fueled with 1-batch ${ }^{\mathrm{h}} . \mathrm{T}_{\mathrm{n}}$ is the irradiation time of cycle 1 though $n-1$ plus time accumulated in the current cycle, $n$. $T_{1}$ is the reactivity limited irradiation time. If an all-fresh core were irradiated continuously, the $T_{1}$ is the irradiation time corresponding to when the allfresh core $\mathrm{k}$-eff $=\mathrm{k}_{\mathrm{c}} \sim 1.005 . \mathrm{k}_{\mathrm{c}}$ is taken to be slightly above unity to ensure criticality at end-of-cycle (EOC) after accounting for uncertainties. The purpose of any batch loading scheme is two-fold. First, fuel that adds positive reactivity, having time less than $T_{1}$, enables fuel with time greater than $T_{1}$ to

\footnotetext{
${ }^{\mathrm{h}}$ Note that $\mathrm{k}$-eff can be converted to reactivity by the equation $\rho=\left(\mathrm{k}-\mathrm{k}_{\mathrm{c}}\right) /\left(\mathrm{k} \times \mathrm{k}_{\mathrm{c}}\right)$ where $\mathrm{k}$ is the $\mathrm{k}$-eff. Kc is the $\mathrm{k}$-eff corresponding to critical. In a physical reactor $\mathrm{k}_{\mathrm{c}}$ equals 1 . In simulation models, this is seldom the case, as is proofed by software validation exercises. However, for the sake of conservatism it is assumed that $\mathrm{k}_{\mathrm{c}} \sim 1.005$ in this study.
} 
continue to be irradiated until its full residency limit, $T_{N}$. $T_{N}$ can be considered the full residency time a batch of fuel assemblies is irradiated prior to discharge as spent fuel. $\mathrm{T}_{\mathrm{N}}$ is set by the peak burnup limit of the fuel-type. Also, the negative reactivity of fuel with burnup greater than $T_{1}$ and less than $T_{N}$ provides reactivity suppression supplemental to other reactivity control mechanisms, e.g., control rods. The irradiation time corresponding to one cycle is $\mathrm{T}_{\text {cycle }}=\mathrm{T}_{\mathrm{N}} / \mathrm{N}$. For simplicity, the cycle-length $\left(\mathrm{T}_{\text {cycle }}\right)$, singlebatch cycle-length $\left(T_{1}\right)$, and full residency time $\left(T_{N}\right)$ will be expressed in irradiation time or full-power days (i.e., not including the time for refueling outages).

The goal was to find a cycle-length, $B U_{\text {cycle, }}$ close to one year (i.e., 365 full-power-days) while ensuring that the total residency time, $\mathrm{BU}_{\mathrm{N}}$, does not allow the fuel peak rod burnup to exceed $10 \%$ Fissions per Initial Metal Atom (FIMA).

Two core power levels were considered, $250 \mathrm{MWth}$ and $300 \mathrm{MWth}$. For the same size of reactor, different power levels correspond to a different burnup rate, shown in Figure 2. Figure 3 shows the change in k-eff (all control rods out) for a single-batch burnup at either $250 \mathrm{MWth}$ or $300 \mathrm{MWth}$. The irradiation time for which the peak rod burnup of 10\% FIMA is reached, $\mathrm{BU}_{\mathrm{N}}$, is 1,400 and 1,200 fullpower-days for the $250 \mathrm{MW}$ th and $300 \mathrm{MWth}$ cases, respectively. The irradiation time for which keff $=1.005$ is reached, $\mathrm{BU}_{1}$, is 950 and 800 full-power-days for the $250 \mathrm{MW}$ th and $300 \mathrm{MWth}$ cases, respectively. Table 5 shows the result of Equation 2 and 3 for one-batch, two-batch, three-batch, fourbatch, and five-batch cores. Recall that the batch scheme may not create a $\mathrm{BU}_{\mathrm{N}}$ greater than the irradiation time corresponding to the peak rod 10\% FIMA limit. The 300 MWth case with three batches gives a cycle-length of 400 full-power-days while still meeting the residency time requirement of 1,200 full-power-days.

Table 5. Cycle-length and residency time in full-power-days for the $250 \mathrm{MWth}$ and $300 \mathrm{MWth}$ power levels assuming different batch schemes.

\begin{tabular}{|c|c|c|c|c|c|}
\hline & & \multicolumn{2}{|c|}{ Cycle-length $\left(\mathrm{BU}_{\text {cycle }}\right)$} & \multicolumn{2}{c|}{ Residency-Time $\left(\mathrm{BU}_{\mathrm{N}}\right)$} \\
\hline $\mathrm{BU}_{\mathrm{N}}$ & No. Batches & $250 \mathrm{MWth}$ & $300 \mathrm{MWth}$ & $250 \mathrm{MWth}$ & $300 \mathrm{MWth}$ \\
\hline $\mathrm{BU} 1$ & 1 & 950 & 800 & 950 & 800 \\
\hline BU2 & 2 & 633 & 533 & 1267 & 1067 \\
\hline BU3 & 3 & 475 & $\mathbf{4 0 0}$ & 1425 & 1200 \\
\hline BU4 & 4 & 380 & 320 & 1520 & 1280 \\
\hline BU5 & 5 & 317 & 267 & 1583 & 1333 \\
\hline
\end{tabular}




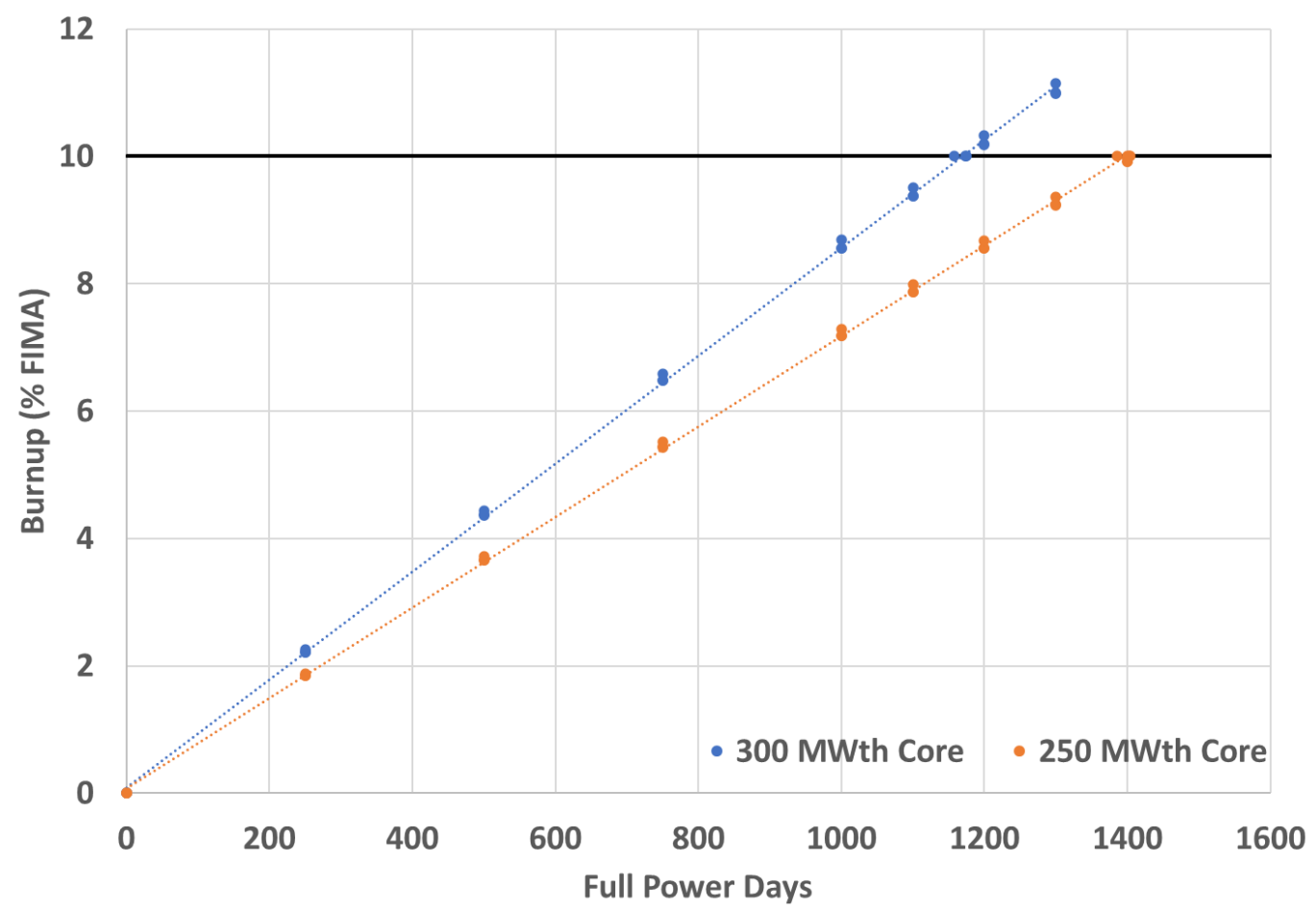

Figure 2. Full-power-days required to reach a peak burnup of 10\% FIMA for a core power of 250 MWth and $300 \mathrm{MWth}$.

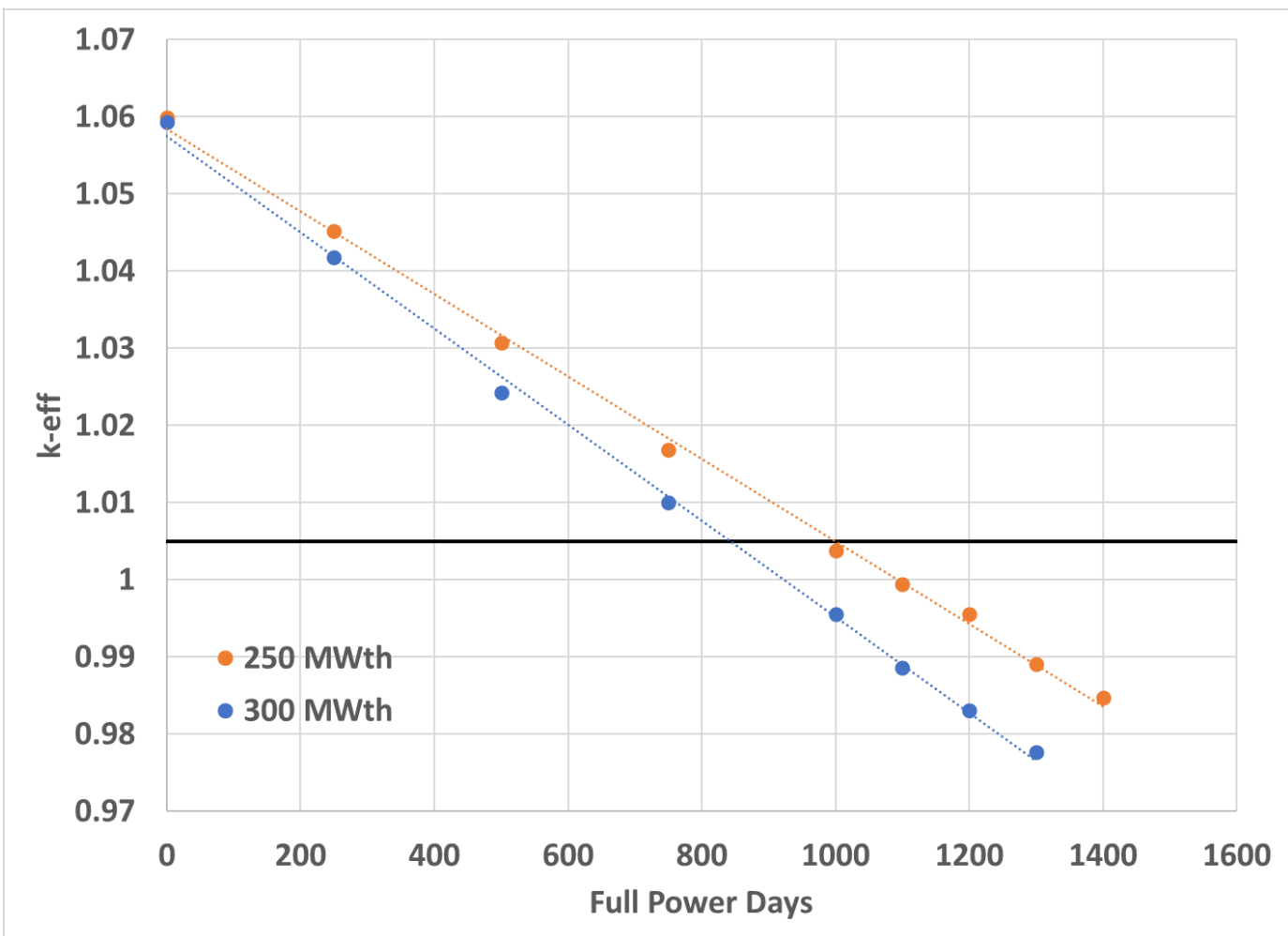

Figure 3. Change in k-eff with time for core power of $250 \mathrm{MWth}$ and $300 \mathrm{MWth}$. 
For the 300 MWth case, the fuel reaches the peak rod 10\% FIMA limit in 1,200 full-power-days. Dividing the core into three-batches gives a cycle-length of 400 full-power-days. Note that the k-eff at 400 days is greater than 1.000 , meaning there is excess reactivity at EOC. This was deliberate because sufficient reactivity is always needed to overcome data and simulation uncertainties that could cause the forecasted EOC excess reactivity to be greater than reality. Figure 4 shows the core reactivity for singlebatch, two-batch, and three-batch cores assuming the linear reactivity model ${ }^{i}$. Also, shown is the core reactivity of the actual three-batch core as-modeled. From the figure it is apparent that the actual simulation model with three batches (discussed in a later section) has more excess reactivity than predicted by the linear reactivity estimate. This was an unintended benefit to the reference model because it allows for a reactivity pension to irradiate neutron absorbing materials such as fertile blankets, advanced control rod materials, and some moderating materials; all of which can have a negative reactivity impact on neutron economy.

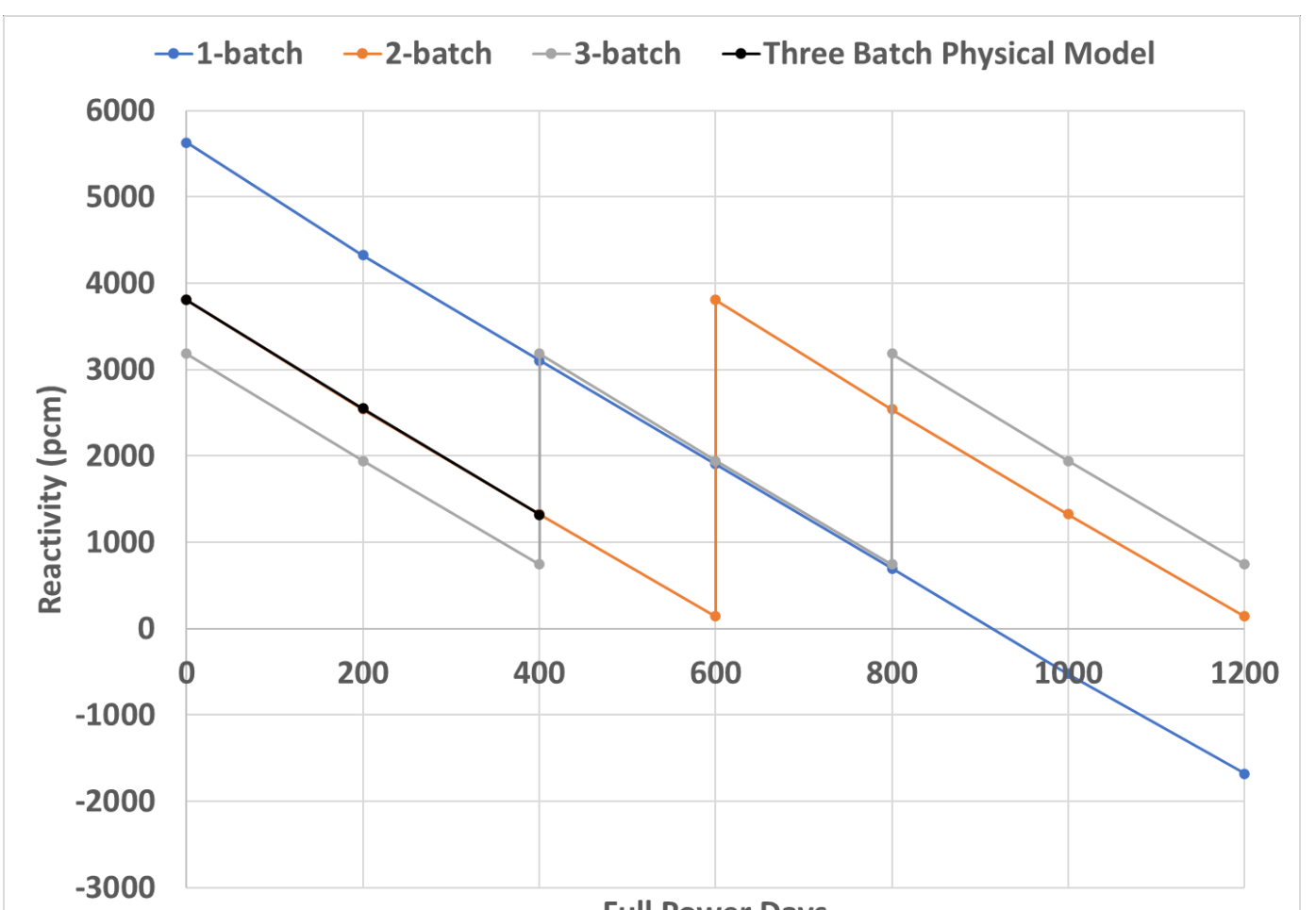

Full Power Days

Figure 4. Core reactivity comparison between single-batch, two-batch, and three-batches using the linear reactivity model as well as the actual core reactivity for the 3-D physical model.

\subsubsection{Reference Core Loading}

Upon completion of the initial core, an updated core was modeled. The model locates fresh, once-, and twice-burned fuel in a repeating pattern so that a third of the core is fresh, once-, and twice-burned fuel. This can be seen in Figure 5, where fresh fuel is in red, once-burned fuel is in orange, and twiceburned fuel is in blue. All experimental/control/safety assemblies are black to highlight the three-batch scheme; reflector assemblies are light grey and shield blocks are dark grey.

To determine the composition for the once- and twice-burned fuel assemblies, we utilize the all-fresh core model; single-batch depletion model. The all-fresh core was burned for two cycles (400 and 800 days respectively), and the average isotopics of the core were taken at each step. Isotopics for the 400-day

${ }^{i}$ The units of reactivity are in 'penti-centi-milli' (pcm) which is equal to: $\rho=100,000 \times(k-1) / k$ 
cycle-length were used as the fuel composition of the once-burned assemblies, and isotopics for the 800day cycle-length were used as the fuel composition for the twice-burned. This scheme is expected to provide a reasonable isotopic composition for the once- and twice-burned fuel. More sophisticated methods can be explored if required.

For the three-batch cycle, the beginning of life k-eff is $1.03920(+/-0.00019)$ resulting in a $-1850 \mathrm{pcm}$ difference from the all-fresh and the three-batch case. The three-batch core has $\sim 1350 \mathrm{pcm}$ of excess reactivity at the end of a 400-day cycle, with a 3-sigma uncertainty of $75 \mathrm{pcm}$. It is not unrealistic for a test reactor to have a large excess reactivity at end-of-cycle (EOC) to carry the negative reactivity burden of neutron absorbing experiments over the requested cycle-length. Neutron producing experiments allow for less fresh fuel to be used in the cycle makeup.

It is important to note that this three-batch reference case is not an equilibrium cycle. Equilibrium cycles are academic constructs where a set refueling pattern is iterated until relevant cycle performances (e.g., core reactivity, peak power, peak burnup) converge. Equilibrium cycles are typically considered in fuel design optimization and related cost-analysis. This digital twin reference cycle represents a simple baseline for which proliferation scenarios may be compared with a sense of realism.

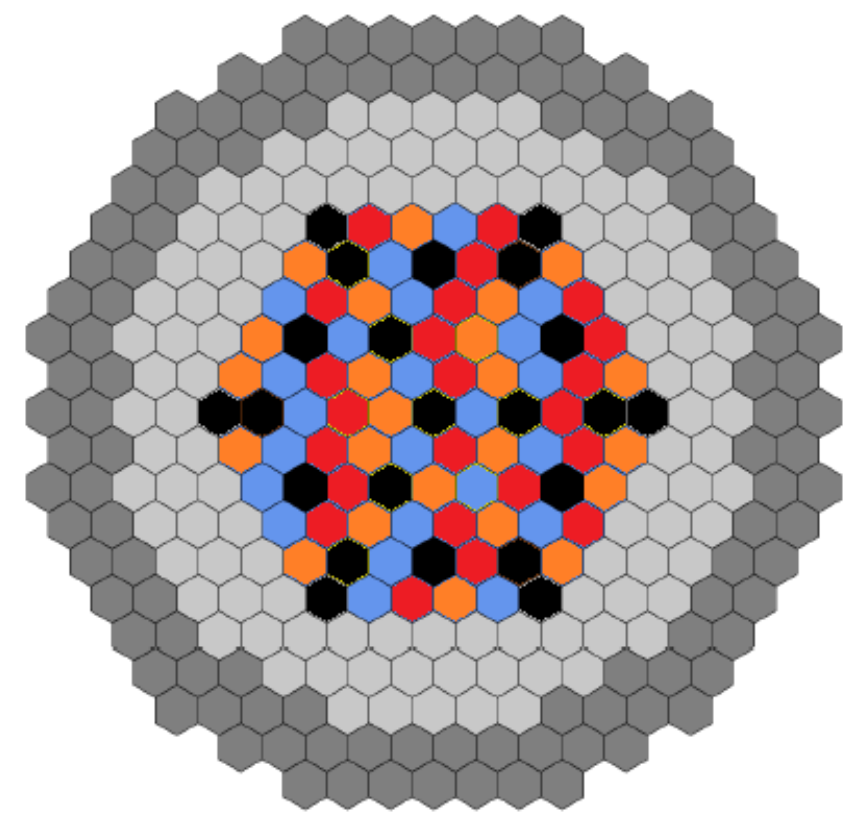

Figure 5. Three-batch core configuration without shuffling, where fresh fuel is seen in blue, once burned fuel in orange, twice burned fuel in red, and experimental/safety/control positions in black.

\subsubsection{Control Rod Hold-Down Worth}

The next step in creating a viable digital twin refence core model was to examine the reactivity holddown worth of the six primary control rods to ensure the core could be shut down in an appropriate manner. The three-batch reference core was used to examine the hold-down worth for this problem. This was performed by inserting the primary control rods in $10 \mathrm{~cm}$ increments from the top of the core until fully inserted to determine the integral control rod worth and the control rod position for the beginning of cycle (BOC). Preliminary work indicated that enriched boron was required to sufficiently bring the reactor subcritical with all primary control rods fully inserted. 
Figure 6 shows the k-eff curve for both natural boron and 85 a/o boron- 10 control rods. For the natural boron, k-eff was nearly 1.000 at full insertion $(110 \mathrm{~cm})$. Said differently, criticality, or cycle startup, occurs by removal of the safety rods alone. This is not acceptable from a core reactivity holddown standpoint. When the boron-10 enrichment was increased to $85 \mathrm{a} / \mathrm{o}$, the k-eff of 1.000 became obtainable at $55 \mathrm{~cm}$, which is $\sim 50 \%$ of the core height. Figure 7 shows the integral rod worth (in pcm) of the six primary control rods as a function of insertion depth. The $85 \mathrm{a} / \mathrm{o}$ boron- 10 control rods have nearly double the control rod worth, when fully inserted, compared to the natural boron-10 worth. For this core, the shutdown margin is $\sim 3700 \mathrm{pcm}$ indicating significant reactivity to shut the reactor down with six 85 a/o boron-10 primary control rods. In the event of the most reactive control rods being stuck fully out $(\sim 1350 \mathrm{pcm})$, the shutdown margin is still $\sim 2350 \mathrm{pcm}$. In the linear range of the $85 \mathrm{a} / \mathrm{o} \mathrm{B}-10$ enriched curve (i.e., near $50 \mathrm{~cm}$ inserted) in Figure 7, the worth of the six primary control rods moving together (as a bank) is approximately $100 \mathrm{pcm}$ per centimeter.

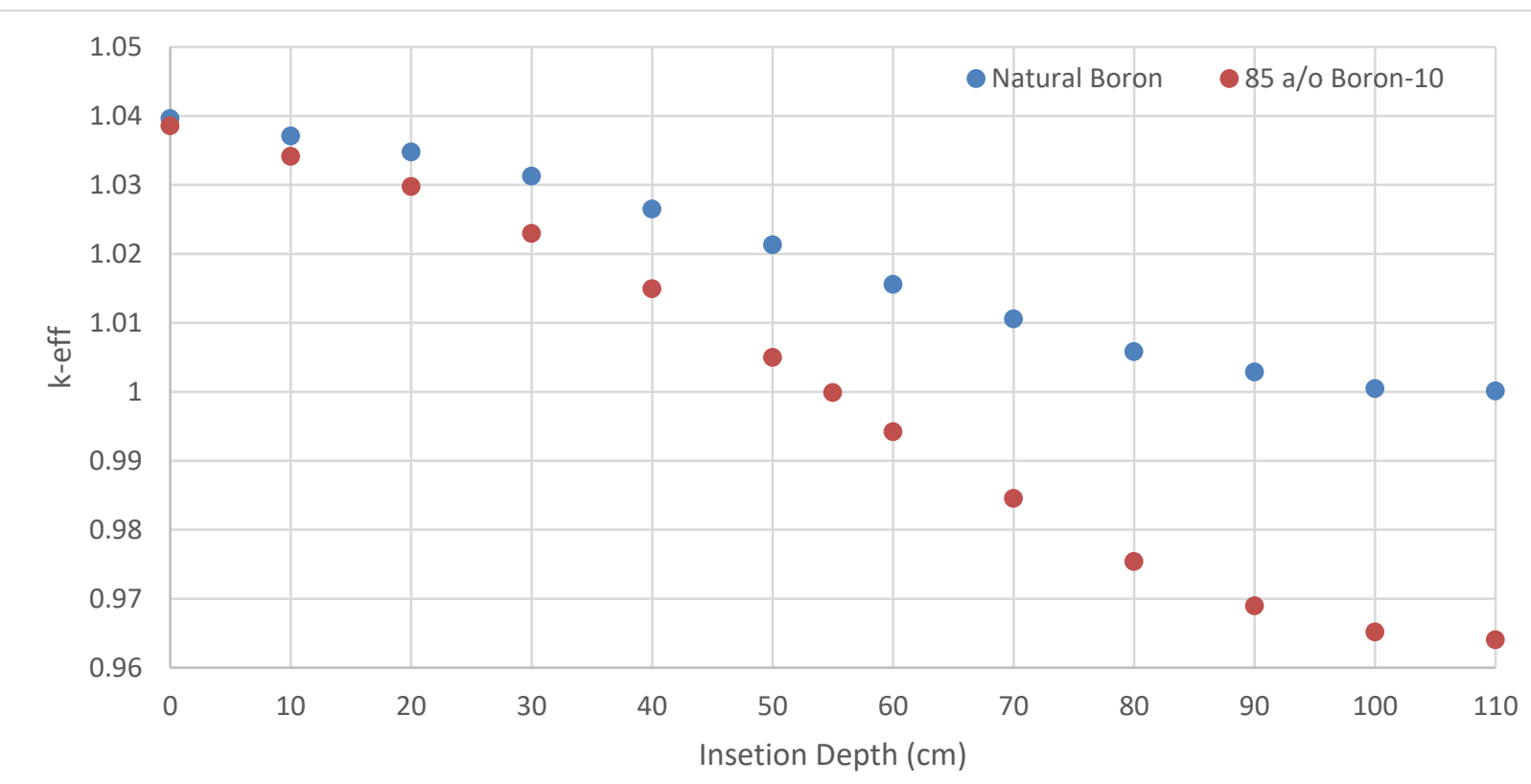

Figure 6. k-eff curve as a function of control rod insertion depth for natural and 85 a/o B-10 control rods.

Since this is not a design study, no effort was made to quantify the discretization of control rod movement or their position indicating accuracy. The General Electric BWR control rod drive motors have a notched position every 6 inches. This means the control blade can only be positioned by 6 inches increment [8]. There is no "in-between" position, the control rod insertion is only in the $[00,06,12, \ldots, 48]$ sequence. However, other concepts provide stepped positions at more refined intervals. The Westinghouse PWR control rod drive mechanism uses a system of magnetic coils, called a "magnetic jack" to locate the control rod in 5/8 inch steps [9]. The FFTF control rod steps were on the order of 0.025 inch [10]. For smaller reactors, it is possible to design control rod steps with much finer position/indication. In TRIGA reactors, it is possible to have control rod positioning and indicating at the sub-millimeter scale [11]. Therefore, it is reasonable to assume that control rod position indication itself is not large source of uncertainty for knowing the control rod position.

The numerical uncertainty of the reactor performance calculation is expected to be a much more significant source of error. Bostelmann et. al. used the SCALE/TSUNAMI code to evaluate the nuclear cross-section related uncertainty for a single control rod surrounded by six metallic U-TRU-Zr fuel 
assemblies, called a super-cell [12]. The SCALE/TSUNAMI software uses General Perturbation Theory to propagate nuclear cross-section uncertainties to the uncertainty of integral data such as k-eff, Doppler coefficient, Na-void worth, control rod worth. The worth of the inserted control rod in this 'super-cell' model was $12,081 \mathrm{pcm}$ with a propagated uncertainty of $2.81 \%$. The largest control rod worth for the GSFR was found to be $1350 \mathrm{pcm}$. Thus, assuming $3 \%$ uncertainty, the reactivity uncertainty associated with all six primary control rods is $1350 \times 0.03 \times 6=243 \mathrm{pcm}$. Given $\sim 100 \mathrm{pcm} / \mathrm{cm}$ of travel, the uncertainty of predicting control rod position due to uncertainties in nuclear data alone is expected to be $243 / 100=2.43 \mathrm{~cm}$. Of course, to know the true uncertainty in control rod worth and core-reactivity, one would need to do a detailed uncertainty quantification study involving mesh convergence studies, numerical solver sensitivities, and nuclear data. However, for the sake of discussion we reasonably assume that the culmination of both calculational and position indication uncertainties is $\pm 2.5 \mathrm{~cm}$. Therefore, a control rod deviation outside of $\pm 2.5 \mathrm{~cm}$ is considered to trigger a more detailed on-site investigation by the IAEA inspectors.

Given the differential control rod worth is evaluated to be $100 \mathrm{pcm} / \mathrm{cm}$ (all six primary rods moving tother), the control rod indication accuracy is taken to be $\sim 200 \mathrm{pcm}$.

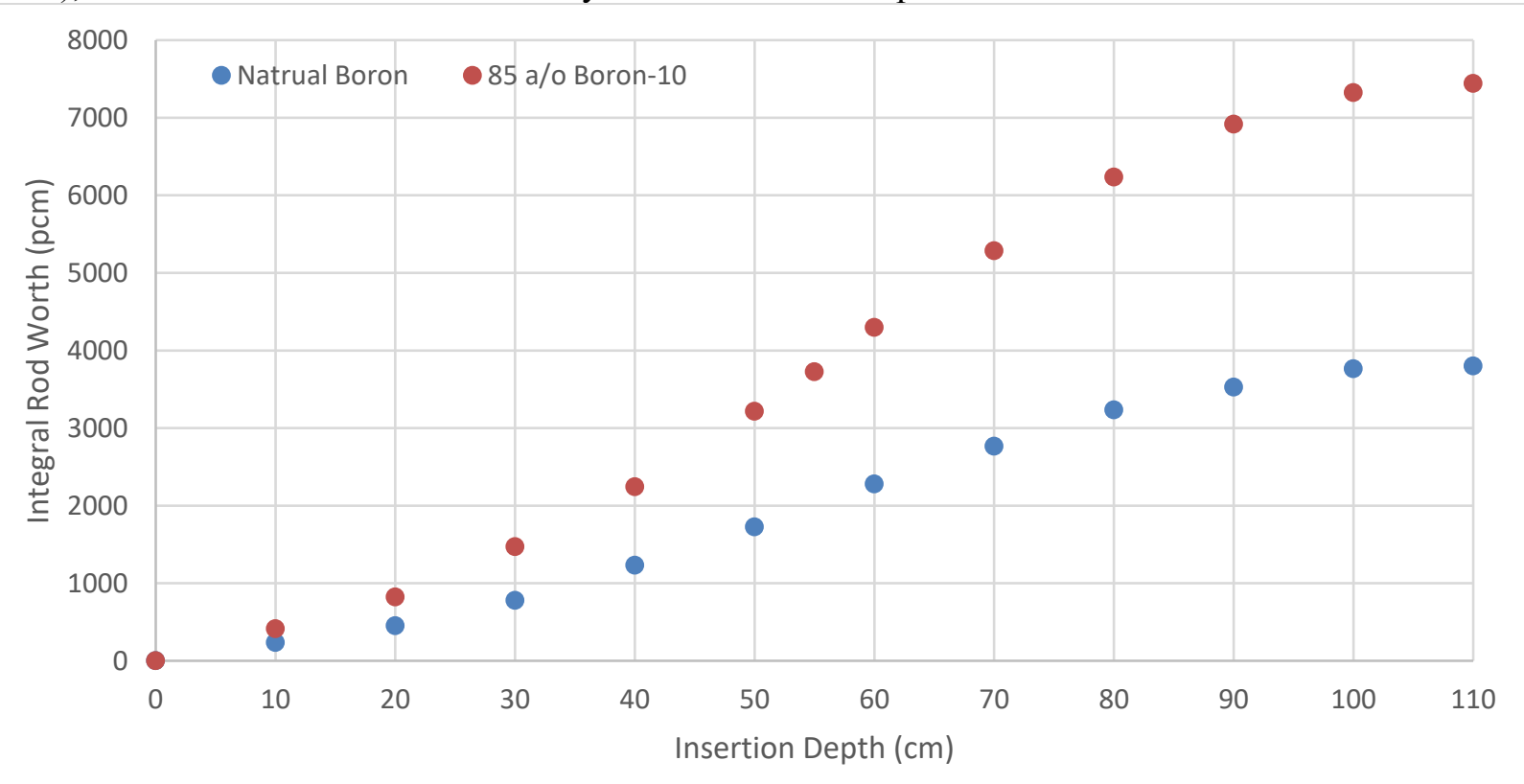

Figure 7. Integral control rod worth for natural and 85 a/o B-10 control rods.

\section{RESULTS}

\subsection{Scenario 1: Diverted Fuel Rods(s) in All Driver Fuel Assemblies}

In this scenario, a number of fuel rods are supplanted with either lead (Pb), stainless-steel (SS), or ${ }^{\text {nat }} \mathrm{U}-$ 10Zr. Pb has a low neutron capture cross-section compared to other materials such as SS, ${ }^{\text {nat }} \mathrm{U}$ (i.e., U-238), or the SFR coolant, Na-23. SS is a common SFR structural material, thus would be an inexpensive material for substituting a fuel-rod. It is assumed that these rods are inserted during fuel fabrication and that all 69 fuel assemblies will contain these 'diversion' rods. Scenarios were considered where one, two, four, eight, or 12 fuel-rods are replaced with $\mathrm{Pb}, \mathrm{SS}$, or ${ }^{\text {nat }} \mathrm{U}-10 \mathrm{Zr}$ rods in every fuel-assembly. The primary goal of this study was to assess the time required to reach $1 \mathrm{SQ}$ of $8 \mathrm{~kg}$ of diverted Pu that would have otherwise been used in fuel rods. Note that such diverted plutonium would not be weapons grade as it has the reactor grade isotopic composition given in Table 1. The secondary goal for this study is to determine the amount of bred plutonium in the nat $\mathrm{U}-10 \mathrm{Zr}$ rods if they could be recovered following irradiation. 
Since fuel rods are being replaced by non-fuel rods for the same core-power, the heat burden for the remaining fuel rods must naturally increase to compensate ${ }^{j}$. Therefore, the peak LHGR is expected to increase. The degree of LHGR increase is also the subject of this study.

\subsubsection{Diversion of Plutonium Fuel}

For this summary, the U-15Pu-10Zr rods replaced with ${ }^{\text {nat }} \mathrm{U}-10 \mathrm{Zr}$ rods are referred to as the diversionrods. Table 6 gives the number of diversion-rods and the corresponding k-eff, calculated by Serpent. Each assembly in the reactor is configured according to the local diagram shown in Figure 8.

As shown in Table 6, as the number of diversion-rods increases the k-eff decreases. This trend is expected since the diversion-rods replace fuel with non-fuel, thus removing fissile material. Table 6 also shows the influence of the neutron absorption properties of $\mathrm{Pb}, \mathrm{SS}$, and U-238 (i.e., $99.3 \%$ of ${ }^{\text {nat }} \mathrm{U}$ ). $\mathrm{Pb}$ has a very low absorption cross-section which is why it has been considered as an alternative reactor coolant to $\mathrm{Na}$ in some fast reactor designs. SS (SS316 as modelled) is comprised of Fe, Ni, Cr which taken together are more neutron absorbing than $\mathrm{Pb}$, but less so than U-238. It is important to note that the reactivity penalty of one $\mathrm{Pb}, \mathrm{SS}$, and ${ }^{\text {nat }} \mathrm{U}-10 \mathrm{Zr}$ is only worth $\sim 200-300 \mathrm{pcm}$. Using the rule of thumb of $100 \mathrm{pcm}$ per $\mathrm{cm}$, discussed in the previous section, this would result in a control rod change of $2-3 \mathrm{~cm}$ control rod perturbation further out than predicted. For two $\mathrm{Pb}, \mathrm{SS}$, and ${ }^{\text {nat }} \mathrm{U}-10 \mathrm{Zr}$, the reactivity worth is $\sim 450-500 \mathrm{pcm}$. This equates into an approximate control rod perturbation of 4.5 to $5 \mathrm{~cm}$. Depending on the uncertainties of the startup control rod prediction and the uncertainties of the RDAS control rod height indicating sensor, this perturbation may escape notice by Safeguards inspectors.

Table 6. The number of diversion-rods and the modeled critical core eigenvalue (StartUp of 3-batch core).

\begin{tabular}{|c|c|c|c|}
\hline Number of diversion-rods & $\mathrm{Pb}$ & $\mathrm{SS}$ & ${ }^{\text {nat }} \mathrm{U}-10 \mathrm{Zr}$ \\
\hline 0 (Reference) & 1.0396 & 1.0396 & 1.0396 \\
\hline 1 & 1.0367 & 1.03645 & 1.03726 \\
\hline 2 & 1.0348 & 1.03419 & 1.03481 \\
\hline 4 & 1.0309 & 1.02954 & 1.03024 \\
\hline 8 & 1.0232 & 1.00807 & 1.02077 \\
\hline 12 & 1.0157 & 1.01138 & 1.01112 \\
\hline
\end{tabular}

The amount of diverted plutonium per cycle due to displacing fuel-rods with $\mathrm{Pb}, \mathrm{SS}$, or ${ }^{\text {nat }} \mathrm{U}-10 \mathrm{Zr}$ can be performed using a hand calculation. The density of U-15Pu-10Zr is approximately $16 \mathrm{~g} / \mathrm{cm}^{3}$. Using the dimension in Table 2 the volume of one metallic fuel slug is $29 \mathrm{~cm}^{3}$. The product of the plutonium weight fraction in $\mathrm{U}-15 \mathrm{Pu}-10 \mathrm{Zr}(15 \%)$ against density and volume yields 70 grams $\mathrm{Pu}$ per fuel-rod. There are 217 fuel-rods per assembly. There are 69 fuel assemblies in the digital twin. One-third of these are replaced every 400 days. Thus, every 400 days $70 \times 217 \times 69 / 3=350 \mathrm{~kg} \mathrm{Pu}$ is loaded into the core. If $1 / 217,2 / 217,4 / 217,8 / 217$, or $12 / 217$ of those rods were replaced by surrogate $\mathrm{Pb}$, SS, or ${ }^{\text {nat }} \mathrm{U}-10 \mathrm{Zr}$ rods, the amount of diverted plutonium would be 1.6, 3.2, 6.4, 12.9, or $19.3 \mathrm{~kg}$ every 400 days. Thus, accounting for this missing plutonium fuel, 1 SQ of weapons-usable (not WG) Pu could be created in 5 cycles ( $\sim 6$ years), 3 cycles ( $\sim 3$ years), 2 cycles ( $\sim 2$ years), 1 cycle ( $\sim 1$ year), 1 cycle ( $\sim 1$ year), respectively.

${ }^{\mathrm{j}} \mathrm{U}-238$ will experience non-negligible fast-fission in a fast neutron spectrum. Therefore, there is fission heating in ${ }^{\text {nat }} \mathrm{U}-10 \mathrm{Zr}$ rod, though significantly less than in actual fuel rods. 

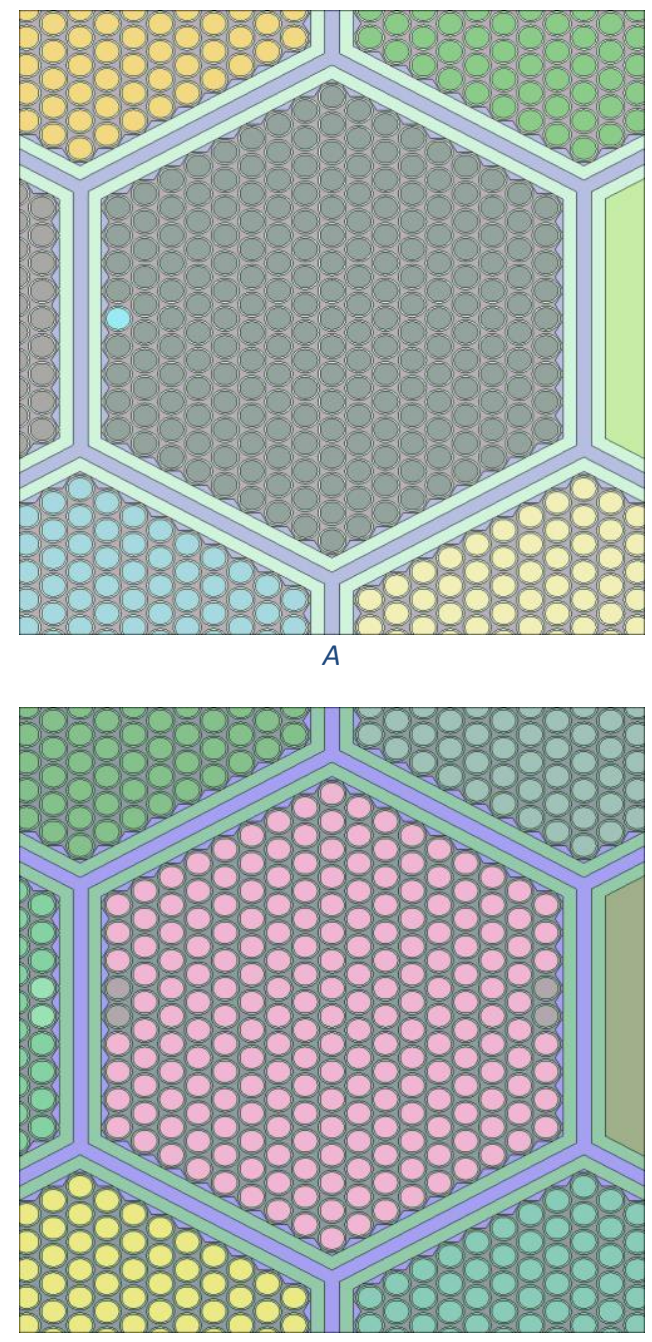

Figure $C$.

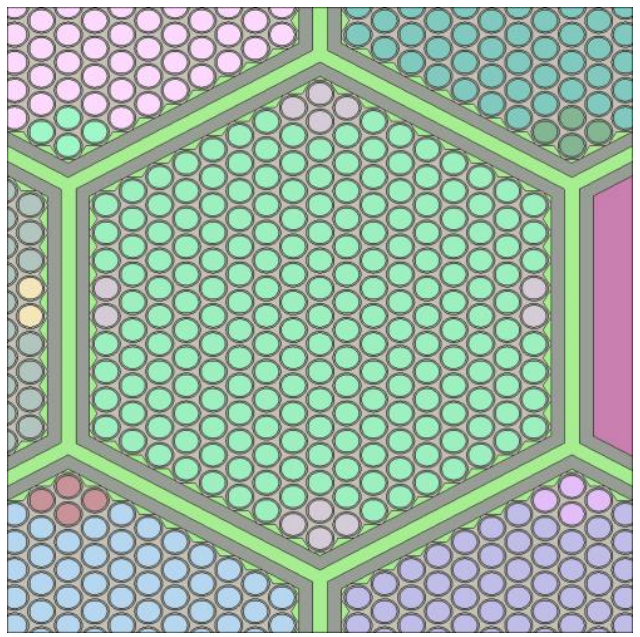

Figure $E$.

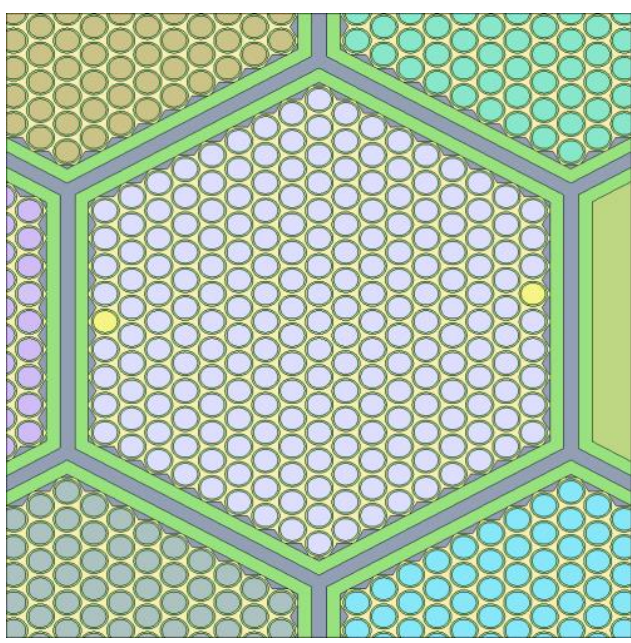

Figure $B$.

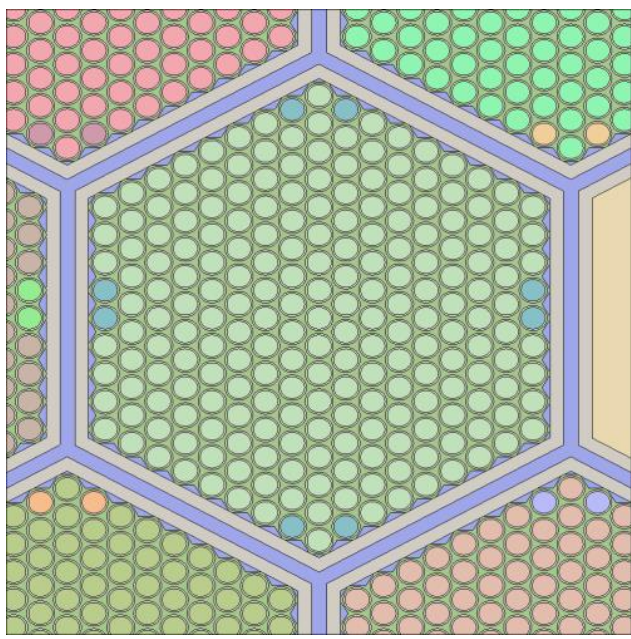

Figure D.

Figure 8. Diagrams of diversion rod positions in a single assembly. (A.) Single diversion rod, (B.) Two diversion rods (C.) Four diversion rods (D.) Eight diversion rods (E.) Twelve diversion rods. 
The decrease over time of the average (over all six fuel assemblies) midplane calculated linear power is shown in Figure 9. The decrease in linear power happens due to the burning of fuel in the central midplane element, and since the power is set to $300 \mathrm{MW}$ in the core, there is a gain in the linear power for the other non-central elements. Figure 9 shows that as more fuel rods are replaced by diversion-rods, the linear power goes up nearly proportionately.

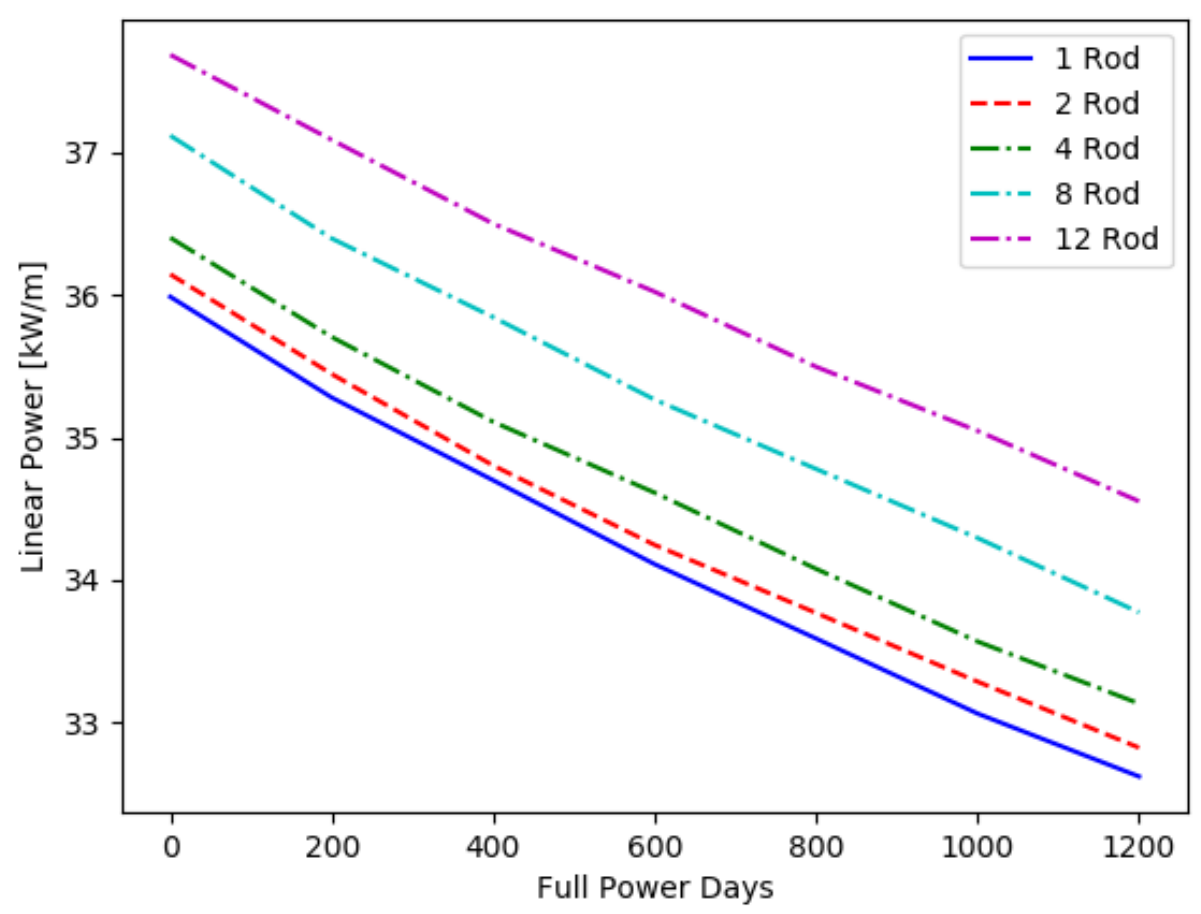

Figure 9. Calculated average midplane maximum linear power for a central hexagonal assembly versus time for all fresh core.

\subsubsection{Misuse by Breeding Plutonium}

The change in k-eff with burnup for the three-batch reference cycle with and without ${ }^{\text {nat }} \mathrm{U}-10 \mathrm{Zr}$ diversion-rods is shown in Figure 10. As expected, when ${ }^{\text {nat }} \mathrm{U}-10 \mathrm{Zr}$ rods are added they act as neutron absorbers and reduce the k-eff. The plutonium created by the diversion-rods being discharged after being thrice burned is given in Figure 11. In the figure, the significant quantity $(8 \mathrm{~kg})$ goal is shown in red. This scenario represents reactor misuse during the due course of normal operation, not an approach to 1 SQ in one yeark.

For the 8-and 12-rod cases, the critical core eigenvalue is below k-eff $=1$ when the 1 SQ goal is met for the three-batch core. This suggests that even though 8- or 12-diversion-rods may be able to breed 1 SQ in one or two batches, doing so would require shorter cycle-lengths with greater than three fuel batches. Reductions in cycle-length and increases in fuel-assemblies-loaded per cycle would draw the attention of inspections. Thus, attempting to create 1 SQ in 1 fuel batch (i.e., $3 \times 400$ days $=$ 1,200 days) without detection is not likely.

\footnotetext{
${ }^{\mathrm{k}}$ Note that each batch resides in the core for three 400-day batches. Therefore, removing the entire fresh fuel batch after only one cycle for the sake of separating $1 \mathrm{SQ}$ from the diversion rods would be a clear break from declared operation.
} 


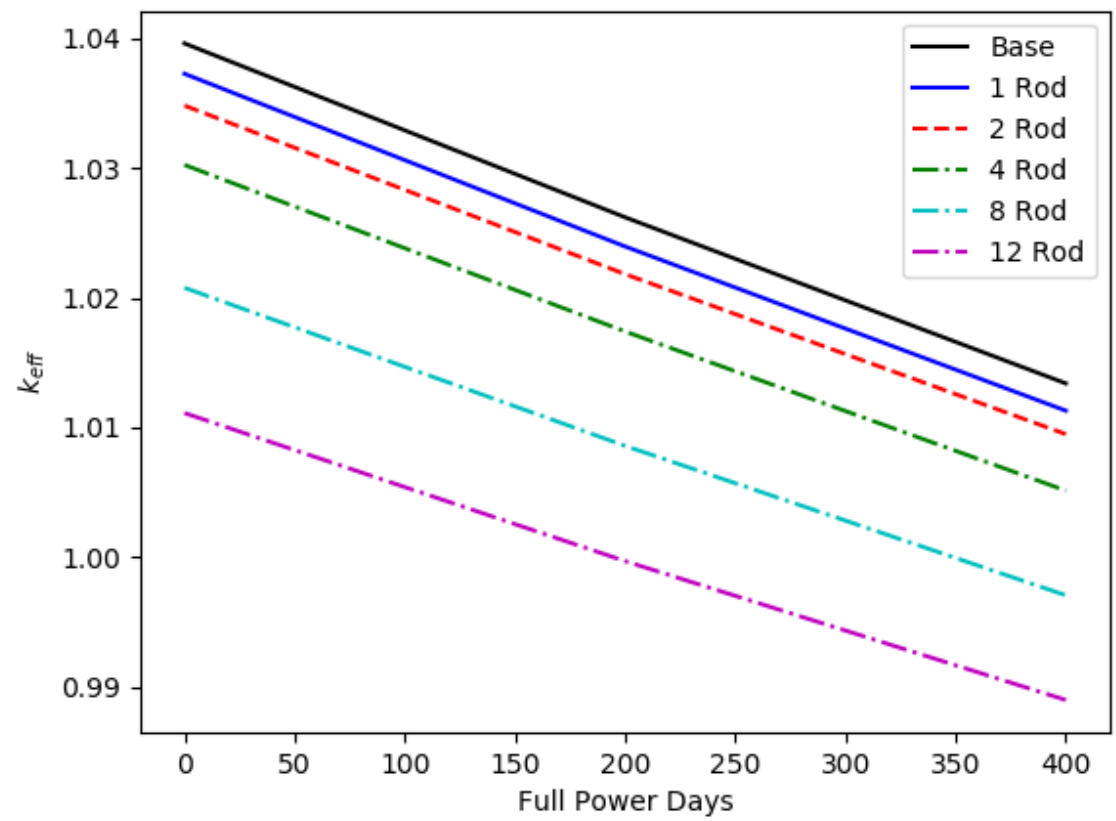

Figure 10. k-eff for a three-batch core to 400 Full-Power-Days assuming one, two, four, eight, or 12- fuel rods per every assembly are replaced by ${ }^{\text {nat }} \mathrm{U}-10 \mathrm{Zr}$ surrogate-rods.

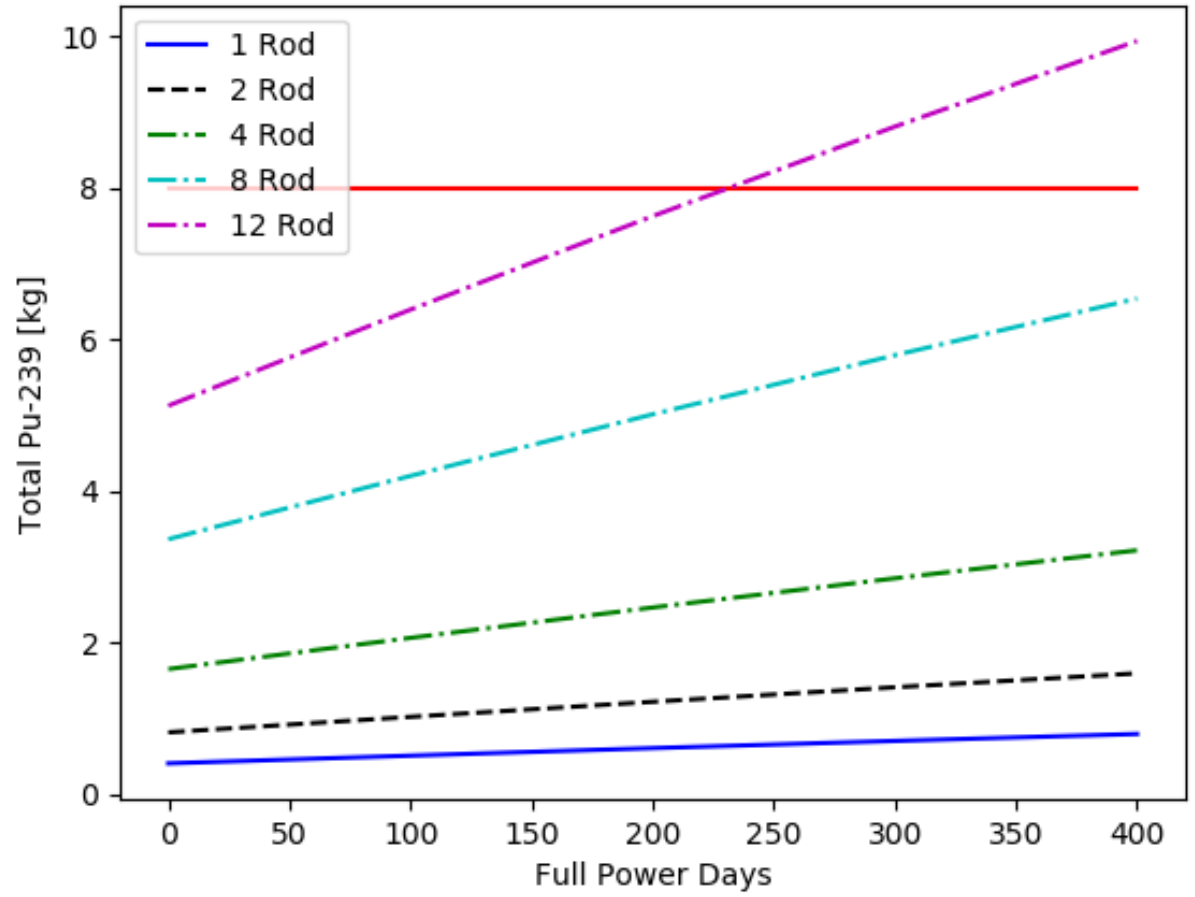

Figure 11. Plutonium produced by a thrice burned batch for $1,2,4,8,12{ }^{\text {nat }} \mathrm{U}-10 \mathrm{Zr}$ surrogate-rods. Note that this plot shows the plutonium created in ${ }^{\text {nat }} \mathrm{U}-10 \mathrm{Zr}$ rods for one batch of fuel over three cycles of irradiation. 
Converting the BOC k-eff data from Figure 10 to excess reactivity and converting the k-eff data from Figure 6 into reactivity hold-down, the primary control rod position corresponding to reactor startup is found. The control rod insertion values corresponding to reactor startup are shown in Table 7. From the table it is apparent that one or two diversion-rods per fuel-assembly create a perturbation of as much as 4 $\mathrm{cm}$ compared to the reference. Depending on the uncertainties of the startup control rod prediction and the uncertainties of the RDAS control rod height indicating sensor, this perturbation may escape notice by Safeguards inspectors.

Figure 11 shows $1 \mathrm{~kg}$ for 1 - and $1.75 \mathrm{~kg}$ for 2- diversion rods per assembly discharged after 1200 days in the core. For following cycles, 1 (1-rod) and $1.75 \mathrm{~kg} 2$-rod) is discharged every subsequent 400 full-power-days. The capacity factor is 0.95 from Table 3 . Thus, it would require approximately 12 years for 1- or 8 years or 2-diverson-rods per fuel-assembly. Therefore, it is reasonable that undetected plutonium generation (reactor misuse) at the SFR is possible, but the proliferator would need to wait at least a decade to achieve this goal. From the diversion analysis for the displaced plutoniumfuel associated with replacing fuel rods with $\mathrm{Pb}, \mathrm{SS}$, or ${ }^{\text {nat }} \mathrm{U}-10 \mathrm{Zr}$ rods, the proliferator would need to wait no longer than approximately six years.

Table 7. Primary control rod position at BOC startup-criticality for one, two, four, eight, or 12 diversionrods per fuel-assembly.

\begin{tabular}{|c|c|c|c|}
\hline Scenario & $\begin{array}{c}\text { Start-Up K-eff } \\
\text { (all rods out) }\end{array}$ & Excess Reactivity $(\mathrm{pcm})$ & Start-Up Inserted CR Position (cm) \\
\hline Reference & 1.03960 & 3809 & 54 \\
\hline 1-rod per assembly & 1.03726 & 3592 & 52 \\
\hline 2-rod per assembly & 1.03481 & 3364 & 50 \\
\hline 4-rod per assembly & 1.03024 & 2935 & 46 \\
\hline 8-rod per assembly & 1.02077 & 2035 & 36 \\
\hline 12-rod per assembly & 1.01112 & 1100 & 24 \\
\hline
\end{tabular}

\subsection{Scenario 2: One U-238 Assembly in an Experiment Location}

To examine the number of full fertile assemblies required to reach $1 \mathrm{SQ}$, an incremental approach was taken. First, a single Fertile Experiment Assembly (FEA) is placed in each experiment location for increasing distances from the center of the core. FEAs for this work were typical of an LMFBR blanket assembly, with a rod diameter of $1.25 \mathrm{~cm}$, a fuel smear of $85 \%$, and a pitch-to-diameter ratio of 1.078 . To accommodate the increase in rod size, the number of fertile rods in the FEA was reduced from 217 to 91. This process increases the heavy-metal share of the FEA volume from $34.03 \%$ to $43.22 \%$.

\subsubsection{Location of a Single U-238 Assembly}

An FEA was placed in each of the four regions of the core that can hold an experimental assembly (row 1, row 3, row 5, row 6). The positions can be seen Figure 1, above. This yields a baseline for the amount of plutonium that can be generated by each assembly position. After this, three FEAs are placed in the core in various positions to determine the plutonium generated. For this initial approach, a burnup calculation was run to 1,200 days without shuffling starting with a core of all-fresh fuel assemblies, (i.e., single-batch burnup).

To examine the effect of adding multiple FEAs to the core, two different parameters were examined; the k-eff as a function of time, and the mass of plutonium generated as a function of time. Through 
examining the k-eff as a function of time, an understanding of the excess reactivity, plutonium buildup, and cycle-length can be explored.

Figure 12 shows the plutonium-generation rate for each of the experimental positions. Table 8 presents the plutonium mass generated for each row as a function of cycles of irradiation. Rows 1 and 3 were found to produce nearly twice as much plutonium for a given amount of time as rows 5 and 6 . For a cycle-length of 400 days, each position produces plutonium with a $\mathrm{Pu}-239 / \mathrm{Pu}$ ratio of greater than 0.98 . Figure 13 shows the effect on k-eff of adding one FEA to each of the experimental positions, where the regression line (seen in blue) shows the trend of the core without experimental assemblies (the base core). The most significant difference is between the assembly in row 1, where there is a $-600 \mathrm{pcm}$ difference at the BOC. From there, the difference in BOC reactivity significantly decreases. Row 3 has a -385 pcm, row 5 has a $-80 \mathrm{pcm}$, and row 6 has a -30 pcm difference. One standard deviation for k-eff is between $25-$ $27 \mathrm{pcm}$, indicating that row 5 and 6 FEA insertions are within a 3-sigma uncertainty of the base core.

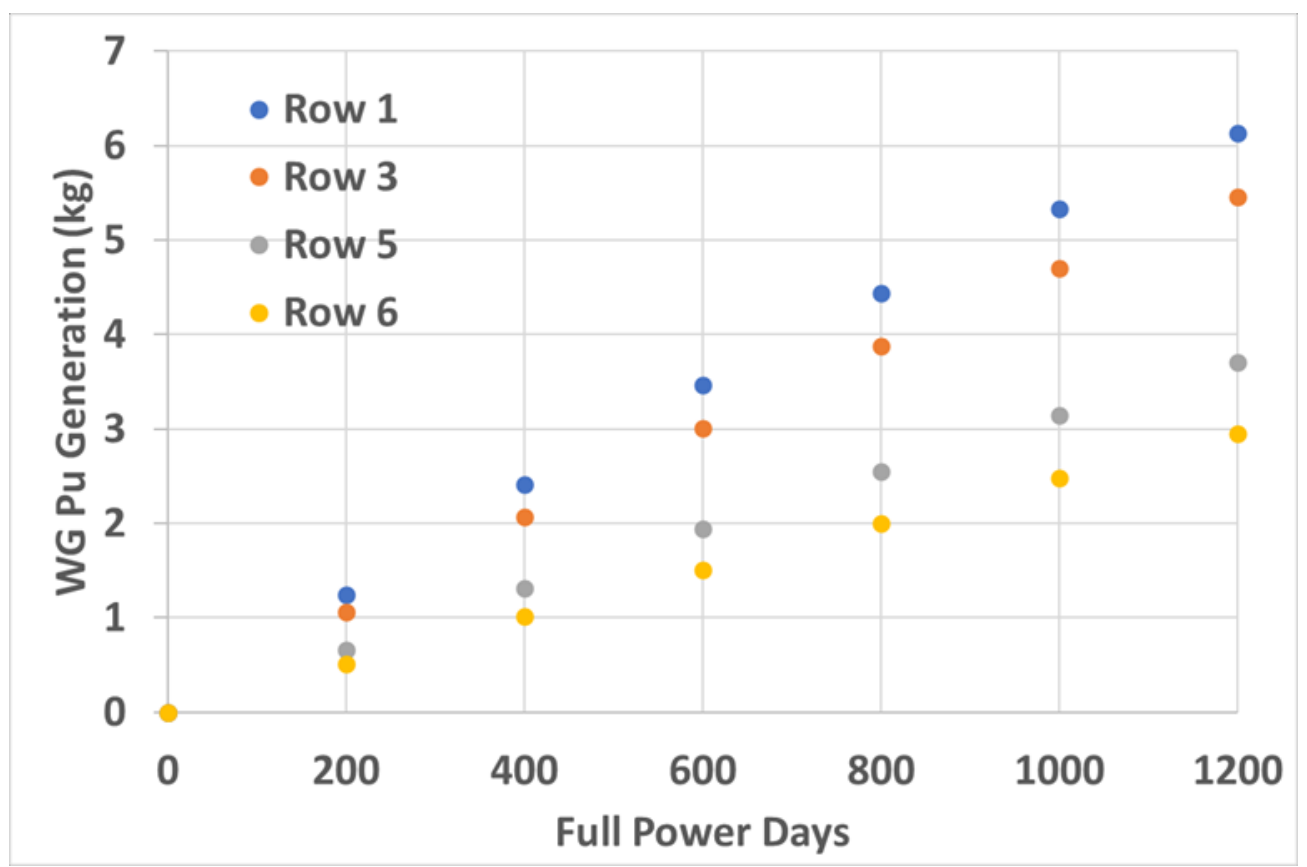

Figure 12. Plutonium mass generated for a single FEA located in one experiment location in row 1, 3, 5, or 6.

Table 8. Plutonium mass generated after one, two, or three cycles.

\begin{tabular}{|c|c|c|c|c|}
\hline & Row 1 & Row 3 & Row 5 & Row 6 \\
\hline 400 days & 2.41 & 2.07 & 1.31 & 1.02 \\
\hline 800 days & 4.44 & 3.88 & 2.55 & 2.00 \\
\hline 1200 days & 6.13 & 5.46 & 3.71 & 2.95 \\
\hline
\end{tabular}




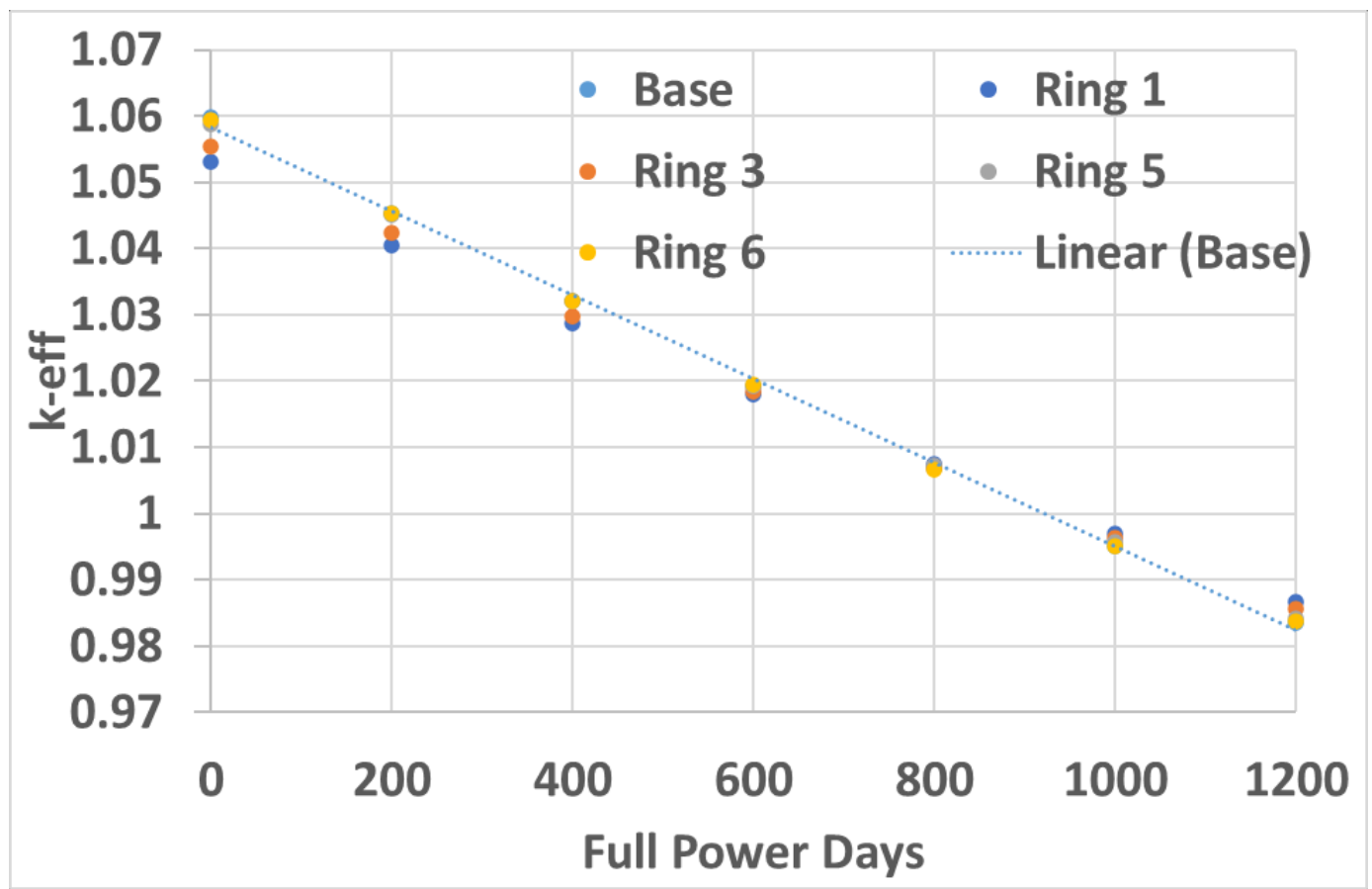

Figure 13. k-eff for a single FEA located in one experiment location in row 1, 3, 5, or 6.

Converting the BOC k-eff data from Figure 13 to excess reactivity and converting the k-eff data from Figure 6 , above, into reactivity hold-down, the primary control rod position corresponding to reactor startup is found for the single-FEA placements. The values are shown in Table 9. From the table it is apparent that location of one or more FEAs in row 5 or row 6 experiment (or reflector) locations would have nil perturbation on the expected primary control rod position compared to the reference. Thus, it is likely that the misuse of the SFR by placing FEAs in the core periphery would escape notice by Safeguards inspectors. From Figure 12, above, this would require approximately 7 years to create $1 \mathrm{SQ}$. Therefore, it is reasonable that misuse of the SFR to create WG Pu is possible with one FEA, but the proliferator would need to wait at least 7 years to achieve this goal.

Table 9. Primary control rod position at BOC startup-criticality for 1 FEA placements.

\begin{tabular}{|c|c|c|c|}
\hline & K-eff & $\begin{array}{c}\text { Change in Excess } \\
\text { Reactivity }\end{array}$ & $\begin{array}{c}\text { Start-Up Inserted CR } \\
\text { Position (cm) }\end{array}$ \\
\hline Reference & 1.05967 & 0 & 54 \\
\hline Row 1 & 1.0534 & -562 & 50 \\
\hline Row 3 & 1.0569 & -247 & $\underline{\mathbf{5 2}}$ \\
\hline Row 5 & 1.05897 & -62 & $\underline{\mathbf{5 4}}$ \\
\hline Row 6 & 1.05889 & -70 & $\underline{\mathbf{5 4}}$ \\
\hline
\end{tabular}

$\dagger$ tnote: These cases were performed with primary control rods fully withdrawn and with all fresh fuel.

\subsubsection{Linear Combination of Single U-238 Assembly Production Rates}

Next, placing multiple FEAs in the core was examined by performing the same depletion steps as before. In total, four configurations were examined.

- One FEA located in the center location, row 1 (same as the single-FEA study) 
- Three experiment locations in row 3

- Three experiment locations in row 5

- Six reflector locations in the hexagonal vertices of row 6

Figure 14 shows the plutonium mass generation for each of these configurations. Placing FEAs in the periphery of the core (rows 5 and 6) show a much slower plutonium generation rate per assembly. Figure 15 shows the reactivity perturbation from the reference case for each of these configurations. The reactivity penalty for placing one FEA in the centermost location, Row 1 , is $-600 \mathrm{pcm}$. There is approximately $-1,200 \mathrm{pcm}$ penalty for irradiating three FEAs in row 3. FEAs inserted in rows 5 and 6 , tend to fall within the in BOC reactivity uncertainty.

Through this examination, the masses of plutonium generated in the single-FEA analysis can be linearly combined to accurately represent plutonium production in core configurations involving multiple FEAs. Table 10 and Table 11 show the difference in plutonium mass generated when estimated based on summing the constituent assembly positions. These tables show that to first order, the plutonium production rates of combinations of FEAs can be represented as linear combinations of the single-FEA production rates.

Table 10. Plutonium mass estimates for a FEA placed in all experiment locations in row 3.

\begin{tabular}{|c|c|c|c|c|}
\hline Time & $\begin{array}{c}\text { Mass }(\mathrm{kg}) \text { Single } \\
\text { Assembly }\end{array}$ & $\begin{array}{c}\text { Mass Estimate } \\
(\mathrm{kg})\end{array}$ & Mass $(\mathrm{kg})$ - Three Assemblies & $\begin{array}{c}\text { Difference } \\
(\mathrm{kg})\end{array}$ \\
\hline 400 days & 2.07 & 6.31 & 6.21 & -0.07 \\
\hline 800 days & 3.88 & 11.75 & 11.64 & -0.11 \\
\hline 1200 days & 5.46 & 16.4 & 16.38 & -0.02 \\
\hline
\end{tabular}

Table 11. Plutonium mass estimates for an FEA placed in the experiment locations of row 1 and row 6.

\begin{tabular}{|c|c|c|c|}
\hline Time & Mass Estimate $(\mathrm{kg})$ & Mass $(\mathrm{kg})-$ All Rows & Difference $(\mathrm{kg})$ \\
\hline 400 days & 6.81 & 6.51 & 0.30 \\
\hline 800 days & 12.87 & 12.36 & 0.51 \\
\hline 1200 days & 18.25 & 17.55 & 0.70 \\
\hline
\end{tabular}

Using this linear mixing approach to estimate the minimum positions needed to create the $1 \mathrm{SQ}$ in one 400 day cycle-length, the proliferator would need to utilize the row 1 experiment position and three assemblies in row $3(8.62 \mathrm{~kg})$. Another combination would be to utilize the three assemblies in row 5 and four in row $6(8.01 \mathrm{~kg})$. Note than in any of these scenarios, slightly more than $8 \mathrm{~kg}$ is produced with a ratio of $\mathrm{Pu}-239$ to total plutonium being $\sim 0.98$.

While it is possible to generate $1 \mathrm{SQ}$ of plutonium in one cycle-length using 4-7 FEAs, this would likely cause a significant perturbation to the BOC excess reactivity. If the proliferator were more patient, waiting two cycle-lengths (800 full-power-days), the 1 SQ could be created with less impact on core reactivity. Summing the mass of plutonium production in the four of the six row 6 positions after 800 days gives $8.16 \mathrm{~kg}$. These FEAs would likely have a smaller impact on core reactivity. 


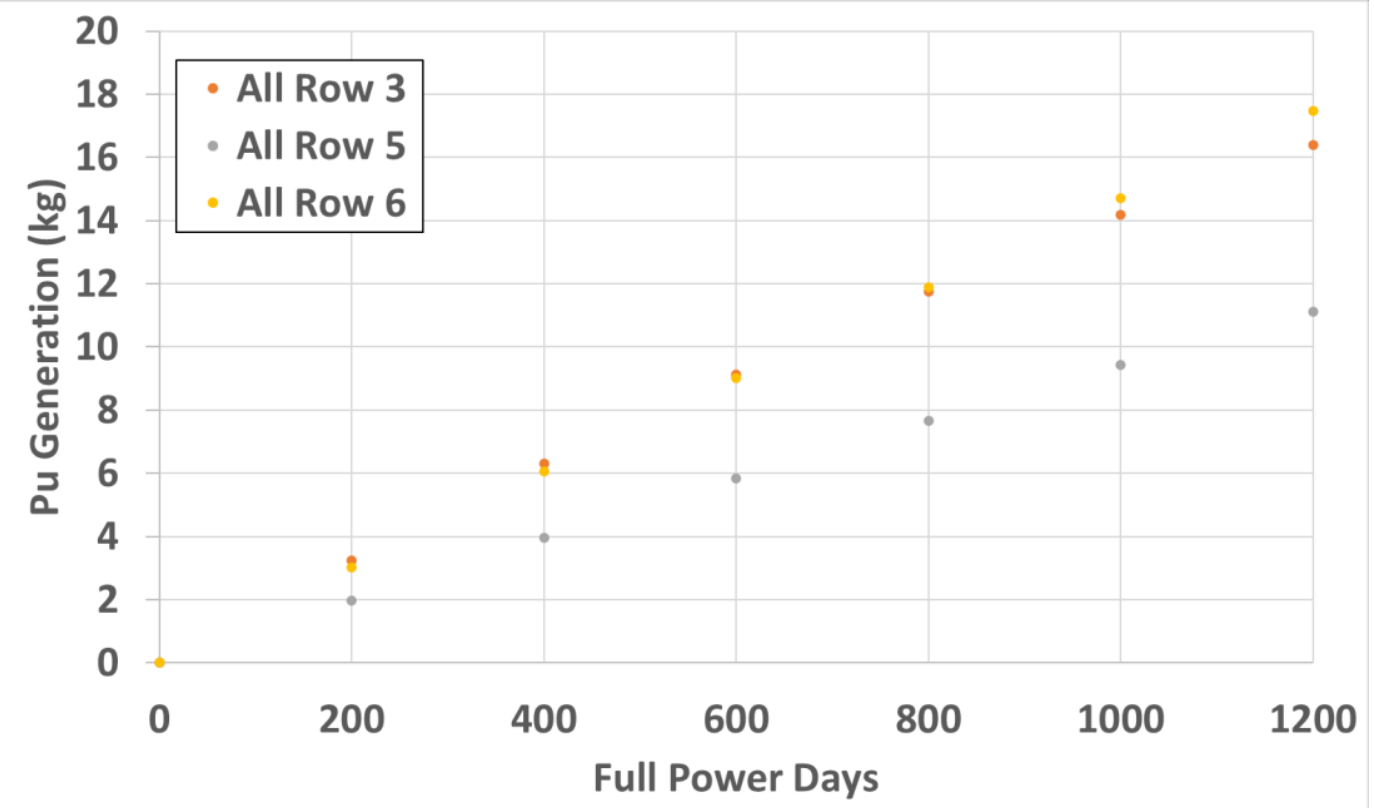

Figure 14. Plutonium mass generation for utilization of all experiment positions in rows 3,5 , or 6 .

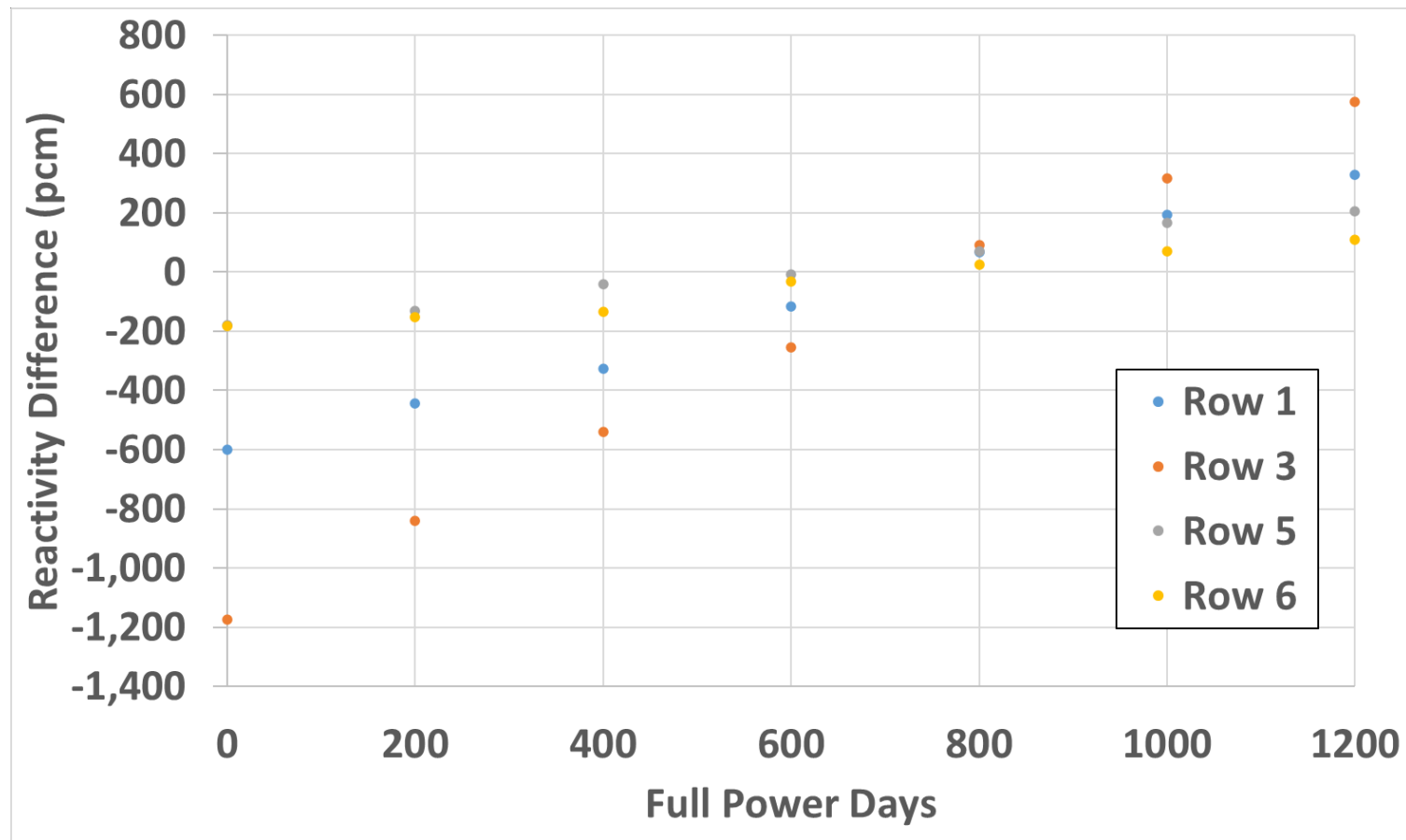

Figure 15. Reactivity perturbation from the reference case: one FEA in the test location in row 1, three in the test locations of row 3 , three in the test locations of row 5 , or six in the six vertex reflector locations of row 6.

\subsection{Scenario 3. Multiple U-238 Assemblies in Experiment Locations}

Utilization of multiple experiment locations in the SFR could potentially create 1 SQ in one or two cycles. However, this would likely lead to a detectable control rod perturbation from expected operation. 
If these perturbations were deliberately small, they could potentially be masked by careful selection of neutron-scattering or neutron-absorbing test assemblies to offset the reactivity effects of the FEAs.

\subsubsection{Start-up Control Rod Position for Multiple U-238 Assemblies}

The addition of FEAs can potentially change the hold-down reactivity worth of the control rods. To investigate the impact of multiple FEAs on primary control rod worth, three separate cases were examined:

- One FEAs in each of the 13 possible irradiation locations (seven experiment and six reflector)

- Two FEAs in row 3 and four FEAs in row 6

- Two FEAs in row 5 and six FEAs in row 6

The 13-FEA case provides a bounding assessment of the hold-down wroth impact. The other two cases are both expected to produce 1 SQ of plutonium in a single cycle with minimum impact on core neutronics.

Figure 16 shows the estimated critical rod heights for the three-batch reference core and the three separate cases. Placing FEAs in the core has a significant impact on the BOC control rod height. Using 13 FEAs reduces the initial control rod height by over $20 \mathrm{~cm}$. The other two cores show a much smaller deviation ranging in a reduction in the initial control rod height by approximately $2-10 \mathrm{~cm}$. The core configuration with two FEAs in row 3 and four FEAs in row 6 is able to generate $8.13 \mathrm{~kg}$ of plutonium. The core configuration with two FEAs in row 5 and six FEAs in row 6 generates $8.08 \mathrm{~kg}$ of plutonium. Note that the later configuration generates $1 \mathrm{SQ}$ and has a smaller effect on the BOC control rod height. Placing FEAs in the periphery of the core requires more assemblies to be placed. However, they have a much smaller impact on the BOC control rod height. Placing FEAs near the center of the core without the placement of additional 'fueled' experiments would likely draw the attention of a Safeguards inspector given the large variation in the control rod height. The integral rod worth remains relatively unchanged $(<$ $5 \%$ difference) when the control rods are fully inserted. The scenario where two FEAs are placed in row 5 and six are placed in row 6 causes a control rod perturbation less than $2 \mathrm{~cm}$, thus may escape detection. 


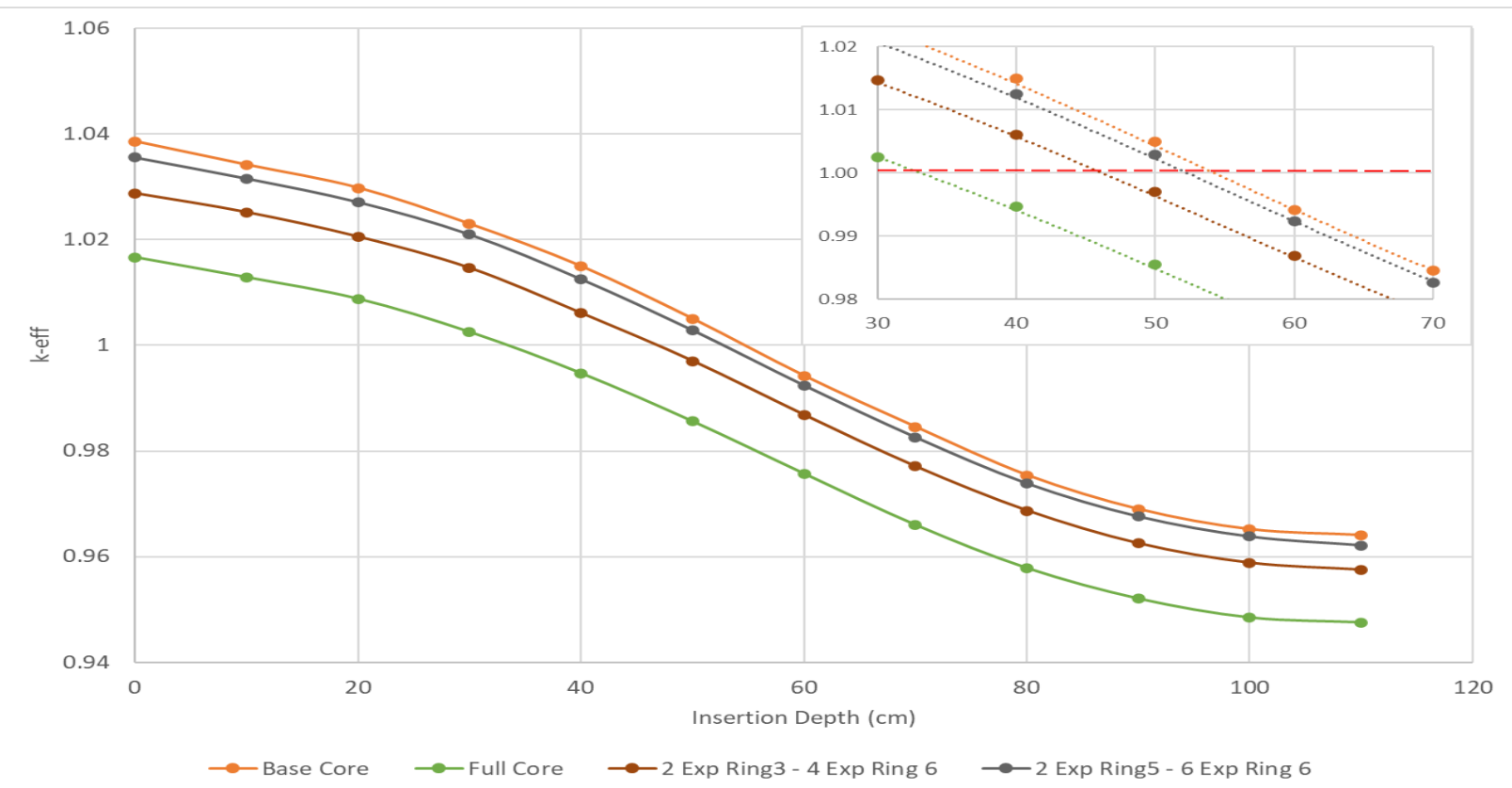

Figure 16. Critical control rod height for varied number of experiments place in the core.

\subsubsection{Masking U-238 Assemblies with Typical Materials Testing}

For this work, three "experimental" assemblies are placed in the reactor: natural uranium-zirconium FEAs, lead, and nickel. For the comparison three assembly positions were selected and used for each calculation, where one experiment assembly was placed in row 1, and two experiment assemblies were placed in row 5, as seen in Figure 17. The natural uranium zirconium experiments shared the same dimensions as the FEA assemblies in the previous section.

Figure 18 shows the reactivity difference between the assembly types and the all-fresh core solution, where the error bars indicate 1-sigma uncertainty. As expected, we find that the lead assemblies act as a better reflector and increases the reactivity for the core lifetime. On the other hand, nickel acts as a neutron poison and depreciates the reactivity in the core. The natural uranium initially starts as a neutron poison, but over the core lifetime plutonium builds into the assembly. At 600-800 Effective-Full-PowerDays (EFPDs) the natural uranium assemblies go from being a neutron poison to a neutron producer due to the plutonium build up. Addition of neutron-reflecting lead assemblies in the early cycles of the production campaign can potentially mask the negative reactivity penalty of FEAs located in row 1 or row 3. Similarly, addition of neutron-absorbing nickel assemblies can potentially mask the reactivity contributions by plutonium for cycles later in the campaign. 


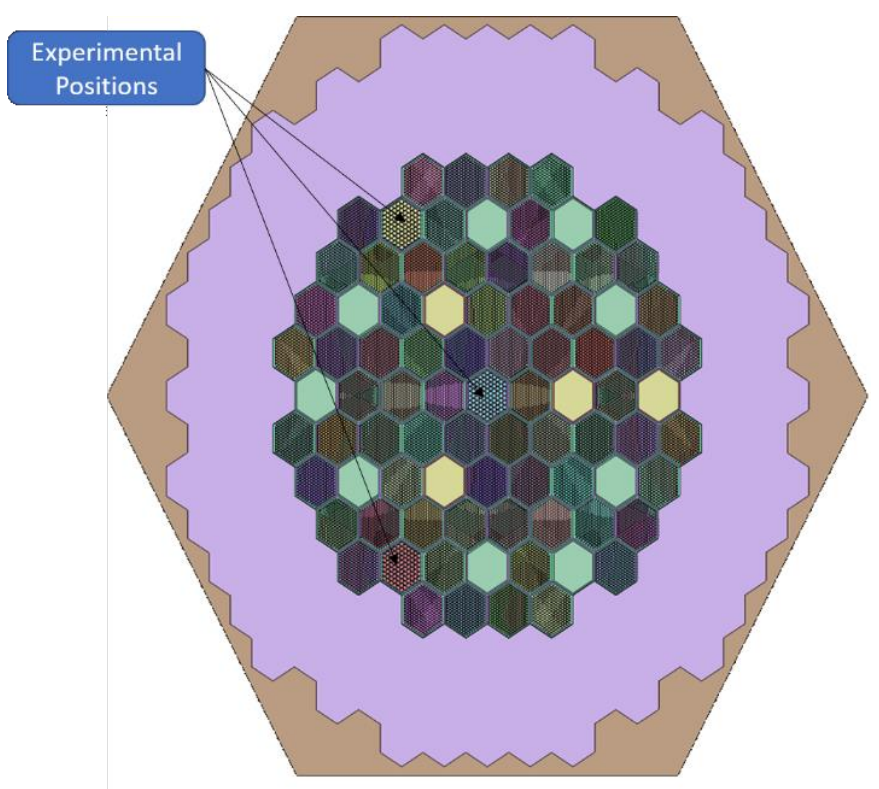

Figure 17. Misuse scenario with three fertile targets (one in row 1, two in row 5).

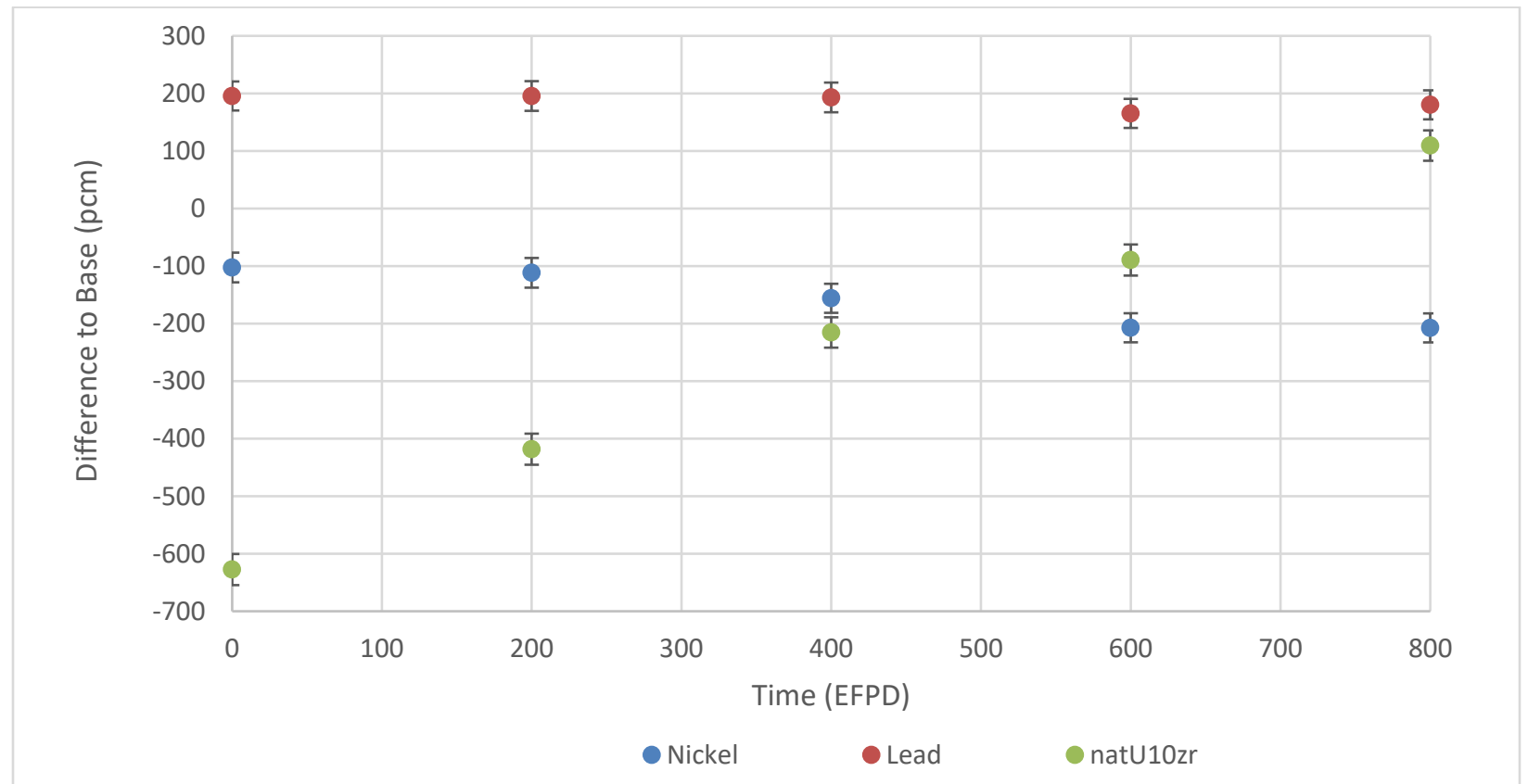

Figure 18. Reactivity influence of inserting three target assemblies (one inner, two outer) having fertile versus inert material types. The unit of penti-centi-milli $(\mathrm{pcm})$ is $1 \mathrm{E} 5 \times \Delta \mathrm{k}$.

\subsubsection{Detecting U-238 Assemblies via Power Distortions}

The safeguard scenarios thus far discuss diversion and misuse detection by monitoring control rod position at various points during the cycle depletion. However, it has been shown that irradiation of FEAs in the core periphery may not be detectable by control-rod position alone. Also, a cunning proliferator may be willing to irradiate multiple FEAs and mask the misuse by placing FEAs in the core periphery as well as employ decoy experiment assemblies (i.e., having positive or negative reactivities to offset the presence of the FEAs) where possible. 
Thus, it is hypothesized that the concentration of FEAs at the core periphery will perturb the radial power profile as indicated by an instrument tree. An instrument tree places thermocouples above select fuel assemblies. The sensed temperature can be correlated back to fuel-assembly power. For this study, the core configuration using two FEAs in row 5 and six FEAs in row 6 is used and can be seen in yellow in Figure 19. Assembly power levels for Beginning of Cycle (BOC) and End of Cycle (EOC) are compared. The comparison is made with the reference three-batch core, as seen in Figure 20. Hex-tract 1 is not shown in this figure as it is nearly identical to hex-tract 3. With the inclusion of FEAs a significant deviation occurs (200-300 kW) in the outer most assemblies where the FEAs are present. This is expected as the FEAs are acting as a neutron poison rather than a reflector for the outermost assemblies. Along with this, the assembly power near the center of the core starts out a $\sim 1 \%$ greater than the base core, but drifts negative. This may be due to a shift in the power from the center of the core, outward.

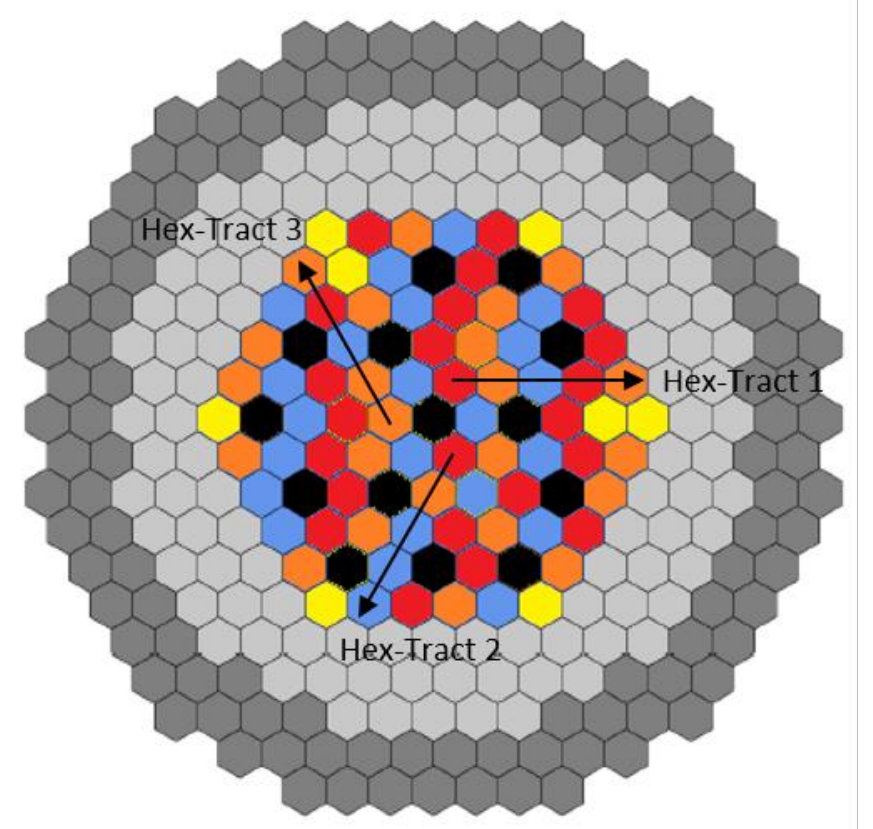

Figure 19. Core configuration for examining assembly power, yellow assemblies indicate FEAs, black assemblies indicate control/safety rods or unused experimental positions. 


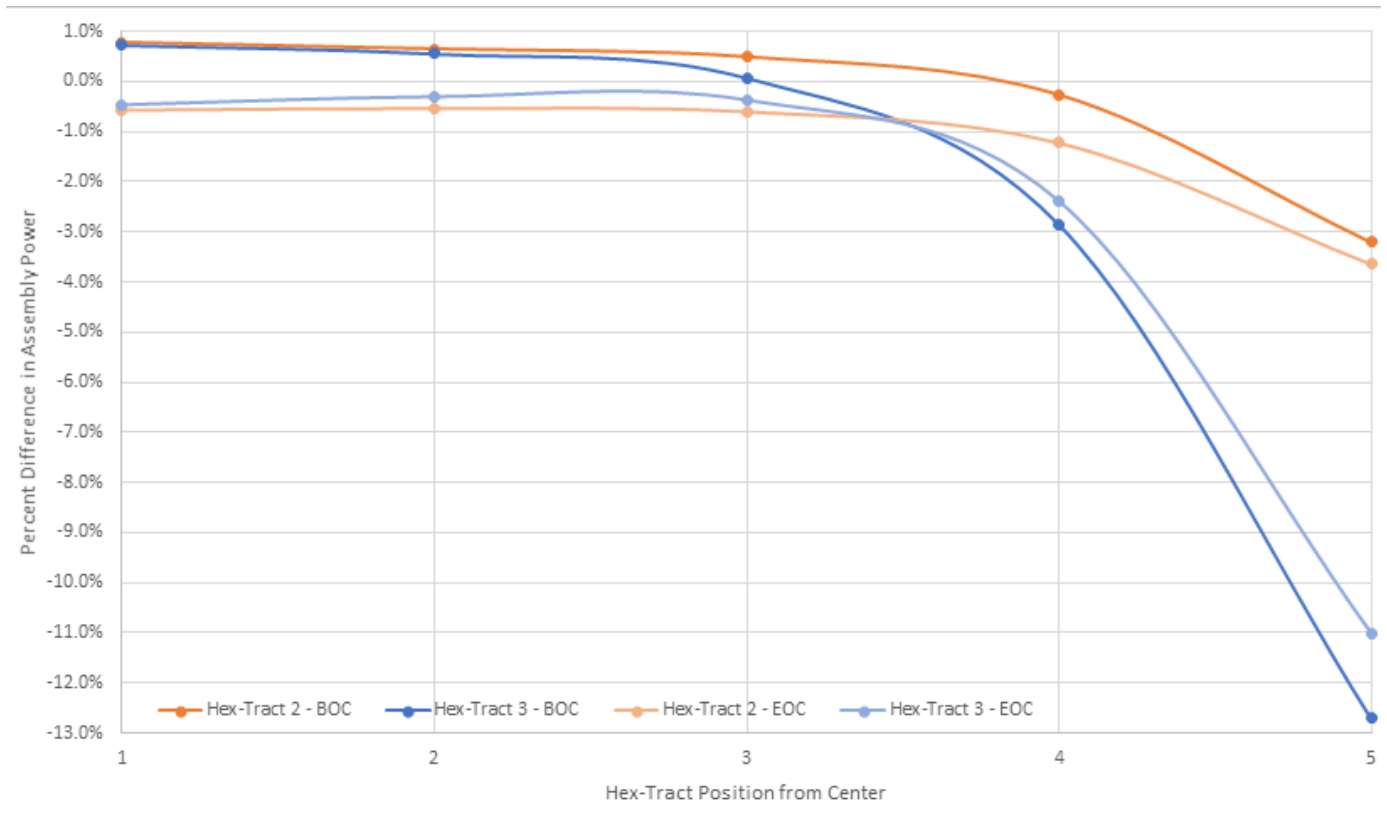

Figure 20. Difference in assembly power level for rows 2 and 3

\section{Conclusions}

SFRs provide a unique challenge for states looking to expand their nuclear technology footprint, while complying with the non-proliferation treaty (NPT). To date, there is little experience with SFR safeguards with respect to the NPT. This is because SFR development has been principally by the original weapons states. In the coming decades, SFR technology is expected to penetrate nuclear markets in the developing world, thus subject to the NPT.

This work has examined how a typical SFR test reactor could be used to divert or produce plutonium. The impacts of these proliferation schemes on expected reactor operation were also examined. Finally, safeguards-by-design solutions using existing SFR plant monitoring technology (i.e., control rod position indication and power distribution monitoring via an instrument tree) were proposed to demonstrate how an SFR under the treaty could be monitored by the IAEA. This study found that most proliferation scenarios could not achieve $1 \mathrm{SQ}$ in 1 year without detection. However, a more patient proliferator may be able to acquire the 1 SQ over the course of a decade without causing the reactor's operation to significantly deviate from the expected (or declared) operation.

\section{REFERENCES}

[1] J. Leppanen, "Serpent - a Continuous-energy Monte Carlo Reactor Physics Burnup Calculation Code (User's Manual)," VTT Technical Research Centre of Finland, 2015.

[2] E. Hoffman, W. Yang and R. Hill, "Preliminary Core Design Studies for the Advanced Burner Reactor over a wide Range of Conversion Ratios," Argonne National Laboratory, ANL-AFCI-177, Argonne, IL, USA, 2006.

[3] Y. Chang, P. Finck and C. Grandy, "Advanced Burner Test Reactor Preconceptual Design Report," Argonne National Laboratory, ANL-AFCI-173, Argonne, IL, USA, 2006.

[4] M. Memmott, J. Buongiorno and P. Hejzlar, "On the Use of RELAP5-3D as a Subchannel Analysis Code," Nuclear Engineering and Design, vol. 240, pp. 807-815, 2010. 
[5] D. Porter and T. Hanchung, "Full-length U-xPu-10Zr ( $\mathrm{x}=0,8,19$ wt.\%) Fast Reactor Fuel Test in FFTF," Journal of Nuclear Materials, vol. 427, pp. 46-57, 2012.

[6] J. Tait, I. Gauld and A. Kerr, "Validation of the ORIGEN-S Code for Predicting Radionuclide Inventories in Used CANDU Fuel," Nuclear Engineerign and Design, vol. 240, pp. 807-815, 2010.

[7] "Fast Reactor Database - 2006 Update," International Atomic Energy Agency, IAEA-TECDOC1531, Vienna, Austria, 2006.

[8] N. R. C. -. T. T. Center, "General Electric Systems Technology Manual (R304B) - Chapter 2.3 (Control Rod Drive System)," [Online]. Available: https://www.nrc.gov/docs/ML1125/ML11258A304.pdf. [Accessed 8 January 2021].

[9] N. R. C. -. T. T. Center, "Westinghouse Technology Systems Manual (R304P) - Section 3.1.3.4 (Control Rod Drive Mechanisms)," [Online]. Available: https://www.nrc.gov/docs/ML2005/ML20057E160.pdf. [Accessed 8 January 2021].

[10] T. A. Pitterle and H. O. Lagally, "Review of FFTF and CRBRP Control rod Systems Designs," Clinch River Breeder Reactor Plant Project Office, Oak Ridge, Tenn. (USA), 1977.

[11] S. Minhat, I. Hussin, M. A. M. M. Taib, N. Joha, M. Mohamed, H. Hasim, M. Rabir, R. Mutalib and Z. Haron, "Development of Automated Controller System for Controlling Reactivity by using FPGA in Research Reactor Application," in $R \&$ D Seminar 2012: Research and Development Seminar 2012, Bangi, Malaysia, September 26-28, 2012.

[12] F. Bostelmann, R. B., W. Zwermann and P. Andreas, "Preliminary SCALE/TSUNAMI Results for the Sub-Exercises of the OECD/NEA Benchmark for Uncertainty Analysis in Modeling of SodiumCooled Fast Reactors," in American Nuclear Society - 2018 Winter Meeting and Nuclear Technology Expo, Orlando, FL, USA, Nov 11, 2018 - Nov 15, 2018.

[13] M. Hussain, F. Reitsma, M. H. Subki and H. Kiuchi, "Advances in Small Modular Reactor Technology Developments, A Supplement to: IAEA Advanced Reactors Information System (ARIS) 2018 Edition, http://aris.iaea.org," International Atomic Energy Agency, Vienna, Austria, 2018. 